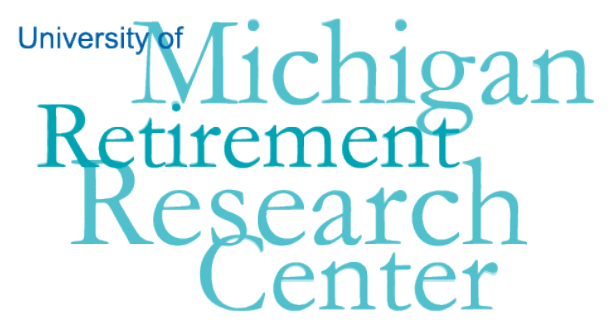

Working Paper

WP 2013-284

\title{
Trends in the Composition and Outcomes of Young Social Security Disability Awardees
}

\author{
Yonatan Ben-Shalom and David Stapleton
}

\begin{tabular}{|l|l|}
\hline $\mathrm{M}$ & $\mathrm{R}$ \\
\hline $\mathrm{R}$ & $\mathrm{C}$ \\
\hline
\end{tabular}

Project \#: UM12-19 



\title{
Trends in the Composition and Outcomes of Young Social Security Disability Awardees
}

\author{
Yonatan Ben-Shalom \\ Mathematica Policy Research, Inc. \\ David Stapleton \\ Mathematica Policy Research, Inc. \\ June 2013 \\ Michigan Retirement Research Center \\ University of Michigan \\ P.O. Box 1248 \\ Ann Arbor, MI 48104 \\ www.mrrc.isr.umich.edu \\ (734) 615-0422
}

\section{Acknowledgements}

This work was supported by a grant from the Social Security Administration through the Michigan Retirement Research Center (Grant \# 5 RRC08098401-04-00). The findings and conclusions expressed are solely those of the author and do not represent the views of the Social Security Administration, any agency of the Federal government, or the Michigan Retirement Research Center.

\section{Regents of the University of Michigan}

Mark J. Bernstein, Ann Arbor; Julia Donovan Darlow, Ann Arbor; Laurence B. Deitch, Bloomfield Hills; Shauna Ryder Diggs, Grosse Pointe; Denise Ilitch, Bingham Farms; Andrea Fischer Newman, Ann Arbor; Andrew C.

Richner, Grosse Pointe Park ; Katherine E. White, Ann Arbor; Mary Sue Coleman, ex officio 


\title{
Trends in the Composition and Outcomes of Young Social Security Disability Awardees
}

\begin{abstract}
A large share of new Social Security Disability (SSD) beneficiaries -- disabled workers and disabled adult children (DAC) -- are under age 40. Better information on the backgrounds, impairments, personal characteristics, and employment outcomes of these beneficiaries would help policymakers develop programs tailored to the needs and circumstances of various subgroups of such beneficiaries. We use administrative data on young SSD awardees first awarded benefits between 1996 and 2007 to examine trends in these awardees' composition and outcomes. We find that the composition of young SSD awardees changed substantially during this period. In 2007, compared to 1996, relatively more SSD awards to individuals under age 40 went to DAC versus disabled workers; to disabled workers and DAC who had received Supplemental Security Income (SSI) benefits, especially as children, versus those with no SSI history; and to disabled workers and DAC with psychiatric disorders versus those with other types of impairments. We also find that disabled workers who received SSI as children are far more likely than those who did not receive SSI as children to earn more than $\$ 1,000$ annually (in 2007 dollars) as of the fifth post-award year; that compared to disabled workers, DAC are considerably less likely to work and earn more than $\$ 1,000$ annually; and that both disabled workers and DAC are significantly less likely to earn more than 12 times the non-blind substantial gainful activity level (SGA) annually than they are to earn more than $\$ 1,000$ annually. We discuss factors that may have contributed to the observed trends.
\end{abstract}

\section{Citation}

Ben-Shalom, Yonatan and David Stapleton (2013). "Trends in the Composition and Outcomes of Young Social Security Disability Awardees.” Michigan Retirement Research Center (MRRC) Working Paper, WP 2013-284. http://www.mrrc.isr.umich.edu/publications/papers/pdf/wp284.pdf

\section{Authors’ Acknowledgements}

We are grateful for the programming assistance of Mathematica's Svetlana Bronnikov; the assistance of the Social Security Administration's (SSA) Paul O'Leary, particularly for the analysis of earnings records; and the comments of David Wittenburg on an earlier draft. This work was supported by a grant from SSA through the Michigan Retirement Research Center (Grant \#5 RRC08098401-0400). The findings and conclusions expressed are solely those of the authors and do not represent the views of SSA, any agency of the federal government, or the Michigan Retirement Research Center. 


\section{INTRODUCTION}

A large share of new Social Security Disability (SSD) beneficiaries are under age 40 (young awardees). ${ }^{1}$ This was not always the case, however. Social Security Disability Insurance (DI) was originally added to Old Age and Survivors Insurance (OASI) in 1956 as an early retirement program for workers age 50 or older with medical conditions that prevented continuation of work (Berkowitz 2000). By 1965, the Social Security Act had been modified so that disabled workers of any age with as few as six quarters of covered employment could qualify for DI. Coverage was also extended to disabled adult children (DAC) of parents who are primary OASI or DI beneficiaries, regardless of the adult child's work history. By 1990, young awardees accounted for about a third of all SSD awardees, falling to about a quarter of all awardees in $2010 .^{2}$ The decline since 1990 in the percentage of young awardees likely reflects the aging of the post-World War II baby boom generation; born between 1946 and 1964, baby boomers were age 26 to 44 in 1990 and 46 to 64 in 2010. Indeed, the number of DI awardees under age 40 rose from about 123,000 in 1990 to 190,000 in 2010, even though the number of DI-insured individuals of that age fell during the same period. ${ }^{3}$ According to the Social Security Administration's (SSA) chief actuary, the DI incidence rate for young workers (age 25 to 44) increased substantially relative to that for older workers (age 45 to 64) between 1980 and 2010 (Goss 2013).

Growth in the number of young beneficiaries has drawn relatively little attention in the public discussion over the pending exhaustion of the DI Trust Fund. The Social Security and Medicare Boards of Trustees (2012) and the Congressional Budget Office (2012) both project exhaustion of the fund in 2016. The public debate on policy changes designed to slow growth in the number of beneficiaries has focused on policies that would encourage employers to retain experienced workers after disability onset—DI's original target population. Such policy proposals would not likely assist youth and young adults with disabilities in establishing productive careers.

For this demographic group, movement away from a disability policy initially designed for older disabled workers toward a policy addressing youth and young adults with disabilities might help to improve their futures while reducing growth in government expenditures for their support. Many young awardees will live in poverty throughout their lives despite the receipt of Social Security benefits and other public support (She and Livermore 2009). Lifetime government expenditures for young SSD awardees are often particularly high, even though their monthly Social Security benefits are typically low relative to those of older DI workers; many remain on the rolls for decades, most will receive Medicare, and they are more likely than older DI workers to receive other benefits, including Supplemental Security Income (SSI) and Medicaid. There is great interest, therefore, in developing policies that will help young adults with disabilities lead more productive, fulfilling lives and rely less heavily in government support. That interest is evidenced by SSA's Youth Transition Demonstration (Fraker and Rangarajan 2009) and the upcoming PROMISE initiative, which is a joint initiative of SSA and the departments of Education,

\footnotetext{
${ }^{1}$ SSD beneficiaries include disabled workers, disabled adult child beneficiaries, and disabled widow(er) beneficiaries. Most in the latter two groups receive their benefits from OASI, not SSDI, and are technically not SSDI beneficiaries.

${ }^{2}$ Based on SSA (2011), Table 35 for DAC and Table 39 for SSDI workers under age 40. DAC who were disabled by age 18 were included with the inception of SSDI in 1956. In 1972, DAC eligibility was extended to include those disabled after age 18 and before age 22 .

${ }^{3}$ Similarly, the number of DI beneficiaries under age 40 rose from about 575,000 in 1990 to 910,000 in 2010 - a 59 percent increase.
} 
Health and Human Services, and Labor (Fraker and Honeycutt 2012). Yet much remains unknown about programmatic and employment outcomes under current policy.

Young awardees differ from older SSD awardees along many dimensions other than age. Many have developmental disabilities, most notably intellectual disabilities. They are also more work-oriented than older awardees (Livermore et al. 2009), have higher employment rates (Mamun et al. 2011), and are much more likely to use work incentives and earn so much that their benefits are suspended or terminated because of work (Liu and Stapleton 2011).

Young awardees may enter SSD via several paths. Before being awarded either disabled worker or DAC benefits, they may have received SSI benefits as children and, if so, were likely to have been disadvantaged in many respects. On the other hand, they may have first entered SSI as adults and then later earned sufficient quarters of coverage to qualify for DI. Still other SSD awardees may have had promising careers interrupted by a major injury or the onset of a chronic illness, or they may be recently disabled veterans. Some DAC from relatively affluent families may have become eligible for benefits only once they reached age 18 or at an older age after a parent retired or died.

The medical, personal, and environmental characteristics of awardees vary substantially. Policies that serve some well might serve others poorly. We have only limited information on which young adults with disabilities demonstrate the greatest capacity to become more self-sufficient under current policy and which show the least capacity to do so. Better information on the backgrounds, impairments, personal characteristics, and environments of young awardees and how those factors relate to employment success in later years would help policymakers develop programs tailored to the needs and circumstances of various beneficiary subgroups.

In this study, we use administrative data on young SSD awardees first awarded benefits between 1996 and 2007 to examine trends in beneficiary characteristics and outcomes. Given that awardees who took different paths to SSD award likely differ in terms of personal characteristics and outcomes, we pay particular attention to differences between disabled worker and DAC awardees and between beneficiaries with and without an SSI history either as children or adults. More specifically, we track (1) trends in the composition of SSD awardees in terms of disabled workers versus DAC and whether they have an SSI history either as a child or adult; (2) trends in characteristics of young SSD awardees such as sex, primary impairment, and benefit at award, separately for the disabled worker and DAC subgroups; and (3) trends in key outcomes such as employment and mortality, by subgroup.

We find substantial compositional changes among young SSD awardees during the study period, with important implications for policies intended to serve the population in the years ahead. In 2007, compared to 1996, relatively more SSD awards to individuals under age 40 went to DAC versus disabled workers; to disabled workers and DAC who had received SSI benefits, especially as children, versus those with no SSI history; and to disabled workers and DAC with psychiatric disorders versus those with other types of impairments.

In terms of outcomes, we find that disabled workers who received SSI as children are far more likely than those who did not receive SSI as children to earn more than $\$ 1,000$ (in 2007 dollars) annually as of the fifth post-award year; that compared to disabled workers, DAC are considerably less likely to work and earn more than $\$ 1,000$ annually; and that both disabled workers and DAC are significantly less likely to earn more than 12 times the non-blind substantial gainful activity (SGA) level annually than they are to earn more than $\$ 1,000$ annually.

As we discuss in detail in the concluding section of this paper, several factors potentially contributed to the observed trends. It is difficult to distinguish between the effects of the various factors, however, because of the overlap in timing. Nonetheless, the factors include rapid growth in the child SSI program since 1989, mostly as a consequence of the Zebley decision, which made it easier for children with 
psychiatric disorders to qualify for benefits; the welfare reform of 1996, which increased incentives to apply for federal disability benefits; the special disability workload, which involved the retroactive award of DI benefits to thousands of SSI-only beneficiaries; the aging of the baby boomers, which likely increased the number of young adults eligible for DAC benefits; and the recession of 2001 as well as the 1999 SGA increase, both of which likely induced increases in DI applications.

The paper is organized as follows. In the next section, we briefly describe the eligibility and benefit rules for disabled worker and DAC benefits. We then describe the data and methods used in the study and present the results. In the final section, we discuss the potential factors contributing to the observed trends. Detailed tables appear in the appendix. 
Page is intentionally left blank to allow for double-sided copying 


\section{DISABLED WORKER AND DAC ELIGIBILITY AND BENEFITS}

To qualify for SSD benefits as either a disabled worker or DAC, an individual must meet SSA's definition of disability. That is, he or she is not able to engage in any SGA because of a disability that is expected to result in death or has lasted or is expected to last for at least one year. In 2013, SGA for nonblind workers is the equivalent of paid, unsubsidized employment that would generate $\$ 1,040$ in earnings (the non-blind SGA amount); for blind workers, the SGA amount is higher, at \$1,740 in 2013.

In addition to having a disability according to SSA's definition, disabled workers need to have earned a minimum of Social Security quarters of coverage (QC) by working and paying Social Security payroll taxes. In 2013, workers earn one QC for every $\$ 1,160$ of earnings per quarter, which is 37 percent of the quarterly equivalent of the non-blind SGA amount. The number of QCs needed to make a young adult eligible for disabled worker benefits is remarkably low, especially before age 31 . As few as 6 QCs are required to qualify before age 24; 6 to 18 QCs at age 24 through 30; 20 QCs at age 31 through 42; and 21 to 40 QCs at age 43 and above. Even though no more than 4 QCs may be earned in a single year, all 4 QCs may be earned in a single quarter. Thus, up to 8 QCs may be earned during a six-month period. ${ }^{4}$ In contrast to disabled workers, DAC are not required to have QCs. Instead, they qualify for SSD benefits through a parent who is an eligible disabled, retired, or deceased worker. To qualify for benefits, however, a DAC's disability onset must occur before age 22, and the DAC needs to be unmarried.

Disabled worker benefit amounts are a function of average lifetime earnings before DI award. After a disabled worker qualifies for benefits, a 5-month waiting period must elapse before any payment is made. Twenty-four months after the first payment is made, disabled workers also become eligible for Medicare. In December 2010, 8.2 million disabled workers of all ages received an average monthly benefit of $\$ 1,068$, whereas 910,000 disabled workers under age 40 received an average amount of $\$ 785$. DAC benefit amounts are equal to 50 percent of the parent's Primary Insurance Amount (PIA) if the parent is living and 75 percent if the parent is deceased. DAC are subject to the same 5-month waiting period as disabled workers, and they, too, become eligible for Medicare 24 months after the first benefit payment. In December 2010, close to 950,000 DAC of all ages received an average monthly benefit of $\$ 679$, and 380,000 DAC under age 40 received an average amount of \$632 (SSA 2011).

Qualified individuals may receive concurrent SSD and SSI benefits, whether receiving SSD benefits as a disabled worker or a DAC. However, the SSI benefit is offset by the SSD benefit; the latter is counted as unearned income. Further, an individual may qualify for both disabled worker and DAC benefits but may receive only a total benefit that is equal to the higher of the two. Many individuals who qualify for either SSI or disabled worker benefits have an incentive to apply for DAC benefits if they are eligible and if the latter is higher than the individual's own DI or SSI benefit. With DAC benefits based on a parent's lifetime earnings, DAC benefits often account for the higher benefit amount. ${ }^{5}$ Eligibility for Medicare adds another SSD application incentive to those initially receiving SSI only.

\footnotetext{
${ }^{4}$ See Burkhauser and Daly (2010) for a thorough discussion of the relatively low earning level needed to qualify for life-long disabled worker benefits before age 31 . The authors also show that young adults may achieve eligibility for disabled worker benefits that exceed the value of existing (or potential) SSI benefits with a relatively low level of wage earnings and that the break-even earning level has fallen considerably since 1980.

${ }^{5}$ Anecdotal evidence suggests that disability lawyers are indeed aware of the potentially higher DAC benefits and actively encourage potential beneficiaries to apply for them (Gates 2012):

"The monthly benefit is likely to be higher, and disability comes with Medicare. Further, disability recipients are not penalized if they are able to earn a little money each month to supplement their
} 
(continued)

disability check (keep it under SGA), unlike SSI recipients . . . These claims can reward the disability lawyer who digs a little deeper. With younger adults pursuing an SSI or disability claim, be sure to inquire about the status of both parents, and whether the alleged onset date should be amended to allow a DAC claim." 


\section{DATA AND METHODS}

Most of the data used in this study come from the 2009 version of the Disability Analysis File (DAF), a data file originally constructed to support analysis of the effects of the Ticket To Work (TTW) program. ${ }^{6}$ The 2009 DAF contains current and historical information from SSA administrative data on more than 22 million Social Security beneficiaries age 18 through 64 who participated in the DI and/or SSI disability programs at any time between January 1996 and December 2009. For this research, we supplemented the DAF data with matched data from the SSI Longitudinal File (SSI-LF) and the Master Earnings File (MEF). We defined the date of SSD award as the month in which SSA first sent an OASI or DI payment to the beneficiary. We then classified awardees into 11 award cohorts from 1996 to 2007 based on the year of the award; we restricted our study population to those first awarded SSD benefits at age 18 to 39. The long time frame allows us to examine compositional changes and to use a reasonably long follow-up period (five years) in constructing longitudinal outcomes.

To examine changes in the composition of SSD awardees in terms of the different paths taken to award and how characteristics and outcomes differ for those following the various paths, we classified SSD awardees according to the type of benefit (disabled worker versus DAC) and their SSI history (no SSI history, SSI history first as children, or SSI history first as adults). This classification scheme led to six analytic subgroups: (1) disabled workers with no SSI history, (2) disabled workers with SSI history first as children, (3) disabled workers with SSI history first as adults, (4) DAC with no SSI history, (5) DAC with SSI history first as children, and (6) DAC with SSI history first as adults.

We separated disabled worker and DAC awardees according to a combination of two variables: beneficiary identification code (BIC) and type of claim (TOC). Disabled workers were required to have a $\mathrm{BIC}$ indicating that they were the primary claimant $(\mathrm{BIC}=\mathrm{A})$ and a TOC indicating a disability case $(\mathrm{TOC}=5)$. DAC were required to have a BIC indicating that they were a child of the primary claimant $(\mathrm{BIC}=\mathrm{C})$ and a TOC indicating that the primary claimant was a deceased worker $(\mathrm{TOC}=3)$, retired worker $(\mathrm{TOC}=4)$, or disabled worker (TOC $=7$ ). We classified individuals in our study population who were not identified according to the above criteria as "unclassified" and report basic statistics for that group as well.

We used information from the SSI-LF to determine whether SSD awardees in our study population had received SSI benefits before they received disabled worker or DAC benefits and whether they first received such benefits as a child (before age 18) or an adult (at age 18 or later). We classified SSD awardees who received SSI benefits only during the five-month waiting period for SSD benefits as not having received SSI benefits before SSD award. For each of the SSD award cohorts 1996 to 2007, we calculated summary statistics, by analytic subgroup, for the following characteristics at the time of award: benefit at award, sex, age group (18 to 19,20 to 25,26 to 30,31 to 25 , and 36 to 40), impairment group (psychiatric disorders, intellectual disability, sensory impairments, back disorders, other musculoskeletal disorders, and other physical disorders), ${ }^{7}$ and type of payee (beneficiary direct, family member, private or public institution, or "Other/Unknown"). Even though information on several other characteristics is available in the administrative data, we expected that the set of characteristics named above would provide a useful picture of any shifts in the composition of SSD awardees.

\footnotetext{
${ }^{6}$ The DAF was previously called the Ticket Research File (TRF).

${ }^{7}$ The seven impairment groups are based on the primary disabling condition as recorded in SSA administrative data.
} 
For each SSD award cohort, we also calculated the cumulative percentage experiencing certain outcomes within five years of the award year (see Appendix Table A.1 for detailed definitions of outcomes): mortality, receiving an SSI payment, suspension or termination of the SSD benefit because of work (STW) in at least one month, annual MEF earnings above \$1,000 (in 2007 dollars), and annual MEF earnings above the annual equivalent of the non-blind SGA level ( $\$ 10,800$ in 2007). We also calculated the cumulative number of months in nonpayment status following the suspension or termination of benefits for work (NSTW months).

All of these additional variables provide useful information about awardees, but must be interpreted carefully. Mortality is of interest primarily as a rough measure of the well-being of SSD awardees; however, it is important to note that changes in unadjusted mortality may reflect shifts in both health status at award due to compositional changes and changes over time in the risk of death, all else equal. Tracking receipt of SSI payments by capturing the extent to which SSD awardees begin or continue to receive SSI benefits provides a more complete picture of benefit use by SSD awardees. Such information is useful for developing a better understanding of recent shifts in the composition of SSD awardees and the implications for policies associated with such beneficiaries. We selected the remaining measures to provide a comprehensive picture of the return-to-work outcomes of SSD awardees. STW and NSTW months are useful indicators of work at a sufficiently high level, but the MEF-based measures provide a more complete picture of work efforts by including those who worked at a level that did not lead to the suspension or termination of benefits. 


\section{TRENDS IN SSD AWARD GROUPS FOR THE 1996-2007 AWARD COHORTS}

In Figure IV.1, we show how the 1996 and 2007 cohorts of young SSD awardees are divided among the analytic subgroups. Of the 148,242 beneficiaries first awarded SSD benefits in 1996, we identified 127,669 (86 percent) as disabled workers and 19,626 (13 percent) as DAC; we were not able to identify the remaining 1 percent of awardees (not shown). ${ }^{8}$ In 2007, the total number of SSD awardees was 153,020, an increase of 3 percent over 1996, with disabled workers representing 78 percent of those awardees and DAC representing 20 percent of those awardees; compared to 1996, the number of awards to disabled workers decreased by 6 percent to 119,635 while the number of DAC awards increased by 53 percent to 30,003 .

The percentages of disabled workers and DAC who had received SSI benefits increased considerably between 1996 and 2007. In 1996, only 1 percent of disabled workers had received SSI benefits first as children, and 17 percent had received SSI benefits first as adults; in 2007, 9 and 20 percent of disabled workers had received SSI benefits first as children and first as adults, respectively. The increase was even greater among DAC. In 1996, 29 percent of DAC had received SSI benefits first as children, and 21 percent had received SSI benefits first as adults; in 2007, 48 and 30 percent of DAC had received SSI benefits first as children and first as adults, respectively.

Figure IV.1. Analytic Subgroups for Young Awardees, 1996 and 2007 SSD Award Cohorts

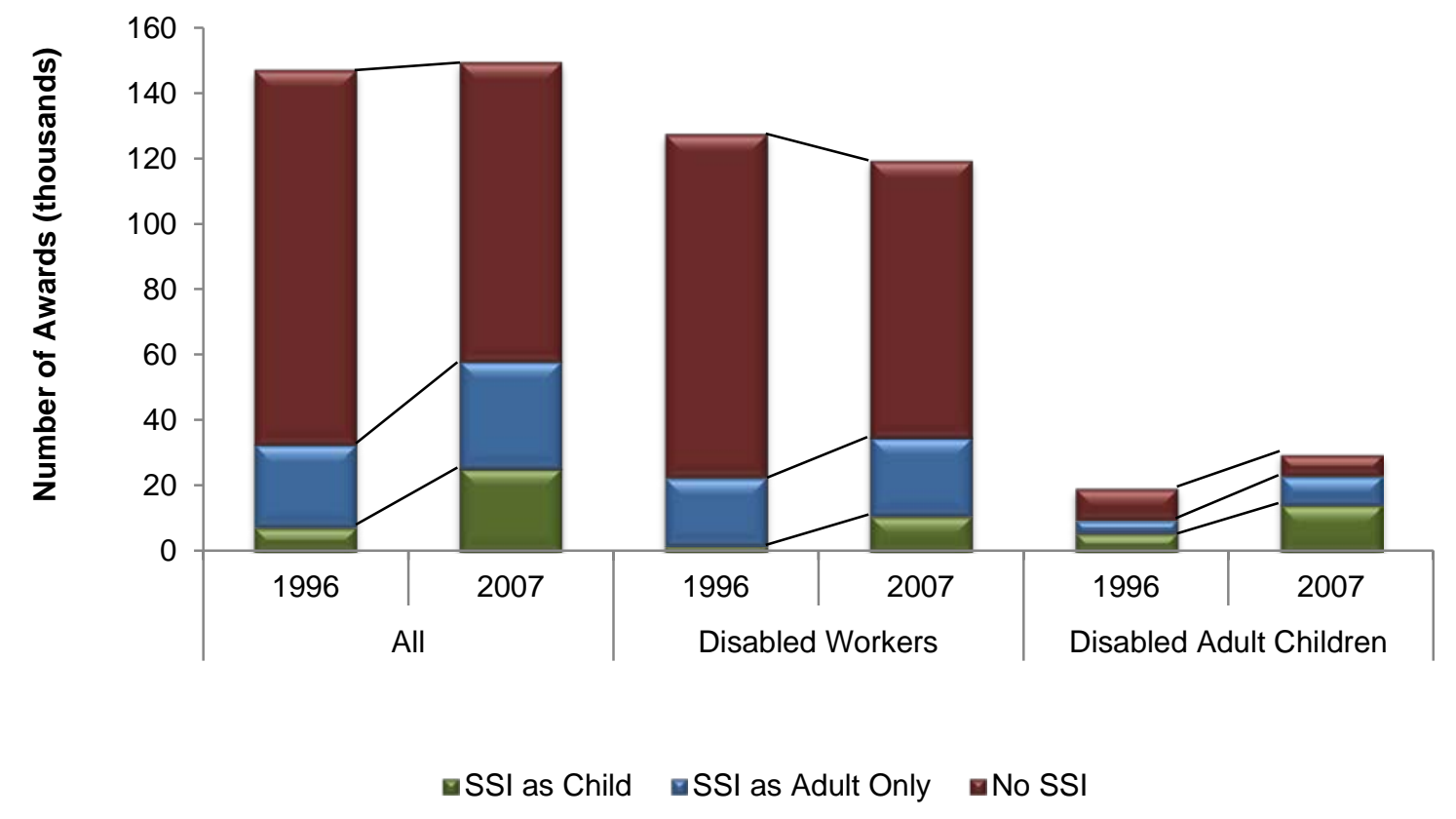

Note: $\quad$ Based on analysis of OASDI beneficiary records in 2009 DAF.

\footnotetext{
${ }^{8}$ In theory, an SSD beneficiary who initially qualifies for disabled worker benefits may also become eligible for DAC benefits once a parent retires or dies. Similarly, an SSD beneficiary who initially qualifies for DAC benefits may become eligible for disabled worker benefits after accruing sufficient QCs. We performed preliminary diagnostics suggesting that few such cases may be found in the data.
} 
In Figure IV.1, we illustrate significant changes in the composition of young SSD awardees between 1996 and 2007, but we do not indicate whether the changes progressed gradually from 1996 to 2007 or occurred during specific periods. To examine the timing of the changes, we show in Figures IV.2 and IV.3 how the size and composition of young SSD awardees evolved from 1996 to 2007. ${ }^{9}$ The overall number of awardees rose by just 3 percent from 1996 to 2007, though with considerable fluctuation along the way. Almost all of the fluctuation was attributable to variation in the number of awards to young disabled workers (Figure IV.2). Notably, the total number of awards fell in 1997 and 2006 compared to the previous year and increased from 2000 to $2002 .{ }^{10}$ In contrast to the trend for disabled workers, the number of young DAC awardees increased steadily from 1996 to 2007 (Figure IV.3). As seen in Figure IV.2, most of the increase in the number of young disabled worker awardees who had received SSI benefits as children occurred between 1999 and 2002, and most of the increase among those who had received SSI benefits only as adults occurred between 2000 and 2002. The percentage of young DAC awardees who had received SSI benefits as children increased steadily from 1996 to 2003 and then increased more slowly between 2003 and 2007 (Figure IV.3). Most of the increase in the percentage of DAC awardees who had received SSI benefits only as adults occurred between 2001 and 2003.

Figure IV.2. Trends for Disabled Workers and DAC, 1996-2007 Young SSD Award Cohorts



Note: $\quad$ Based on analysis of OASDI beneficiary records in 2009 DAF.

\footnotetext{
${ }^{9}$ See Appendix Table A.2 for detailed numbers.

${ }^{10}$ In contrast to what we see in the data for 2006 and 2007, information in the annual statistical report on SSDI for 2010 (SSA 2011) indicates that the number of awards to disabled workers increased substantially after 2006 . The discrepancy between our series and those published by SSA likely arose because we used data from the 2009 version of the DAF while the SSDI report used more recently updated — and therefore more accurate — data.
} 
Figure IV.3. Composition of DAC Awardees, 1996-2007 Young SSD Award Cohorts

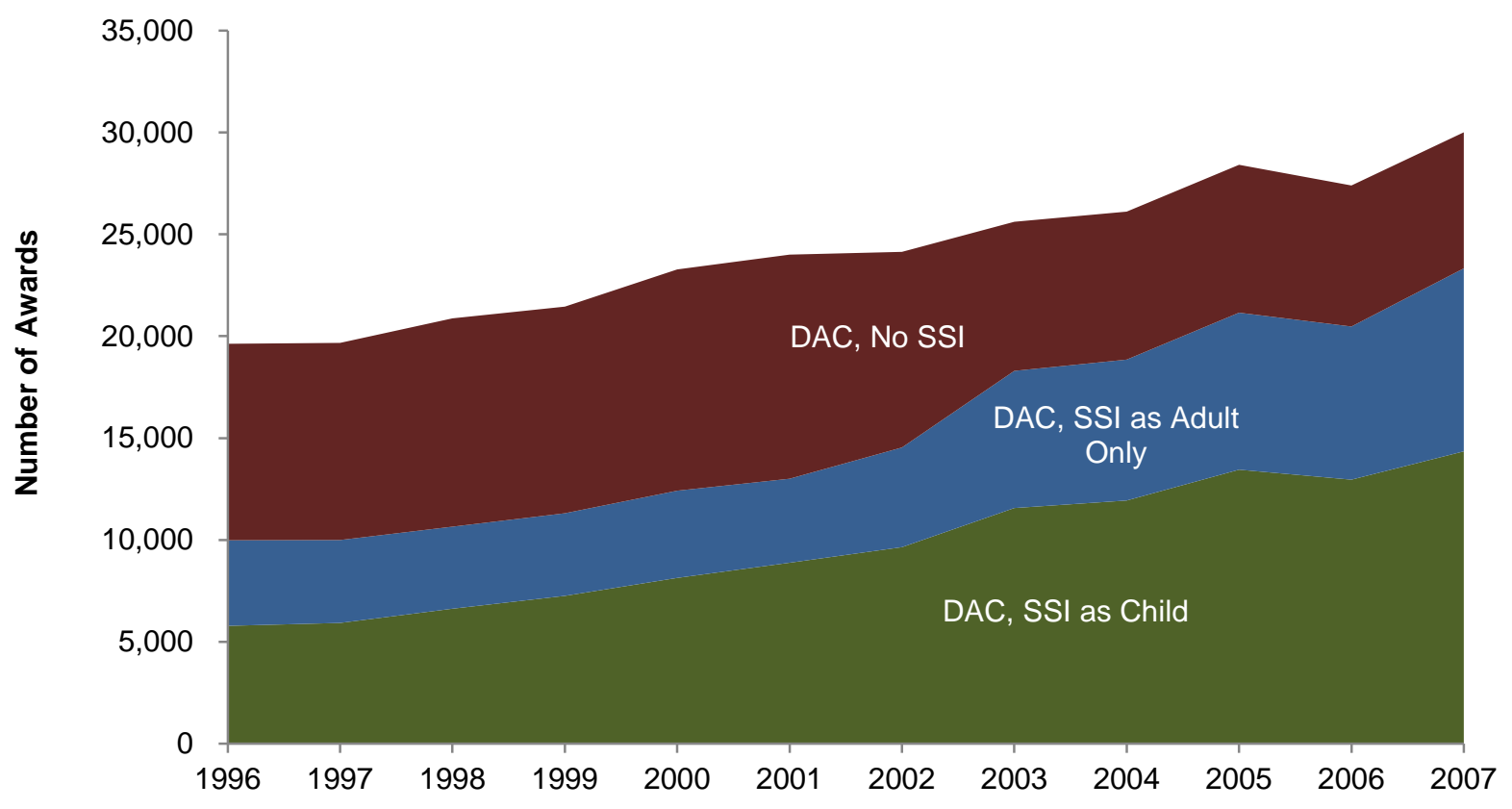

Note: $\quad$ Based on analysis of OASDI beneficiary records in 2009 DAF. 
Page is intentionally left blank to allow for double-sided copying 


\section{TRENDS IN CHARACTERISTICS AT AWARD FOR THE 1996-2007 AWARD COHORTS}

We now compare across annual award cohorts in terms of beneficiary characteristics at award in order to show how the composition of subgroups in terms of personal characteristics changed over time. Although new DAC awards represent a minority of new SSD awards to individuals under age 40, the DAC share of awards has been steadily increasing. Further, the share of DAC awards is expected to continue increasing as the baby boom generation ages and more parents of potential DAC awardees qualify for disability or retirement benefits (see concluding section). We therefore show trends in awardee characteristics separately for disabled workers and DAC. Each series begins with the 1996 cohort and ends with the 2007 cohort. In the figures below, we present comparisons across the 12 award cohorts, with the award year on the horizontal axis and the beneficiary characteristic measure on the vertical axis. In the paper's concluding section, we discuss potential explanations for these trends.

\section{A. Trends for Disabled Workers}

In Figure V.1, we show trends for selected characteristics of young disabled worker awardees, by subgroup. ${ }^{11}$ Counts by subgroup (no SSI, SSI as child, and SSI as adult only) are in the top left panel to facilitate comparison of trends across characteristics.

\section{Mean Benefit at Award}

The mean benefit at award is considerably higher for disabled workers with no SSI history than for those who received SSI as children or adults; for the latter two groups, means of benefit at award are remarkably similar in both level and trend (top right panel). For those with no SSI history, the mean benefit at award (in 2007 dollars) was lowest in 1998 (\$813) and highest in 2004 (\$894). For those who received SSI as children, the mean benefit at award ranged from a low of $\$ 440$ in 2001 to a high of $\$ 520$ in 2006 and 2007; for those with SSI history as adults only, it ranged from a low of $\$ 477$ in 2001 to a high of $\$ 541$ in 2006 . These trends suggest that disabled workers in later cohorts had somewhat higher average lifetime earnings before DI award than those who entered DI earlier in the period.

\section{Percent Female}

We observed a notable increase in the percentage of disabled worker awardees who were female, especially among those who did not receive SSI as children (middle left panel). The increase was fairly steady from 1996 to 2006 among those with no SSI history, but all of the increase for those with SSI history as adults occurred between 1996 and 2002. These trends presumably reflect the growth in the percentage of women who met DI earnings history requirements and, potentially, the shift from Temporary Assistance for Needy Families (TANF) to SSI and, subsequently, to DI among low-income single mothers following the welfare reform of 1996.

\footnotetext{
${ }^{11}$ See Appendix Tables A.3 and A.4 for detailed counts and percentages, respectively. See Appendix Table A.5 for the mean benefit at award.
} 
Figure V.1. Selected Cohort Trends for Young Disabled Worker Awardees, by Subgroup, 1996-2007
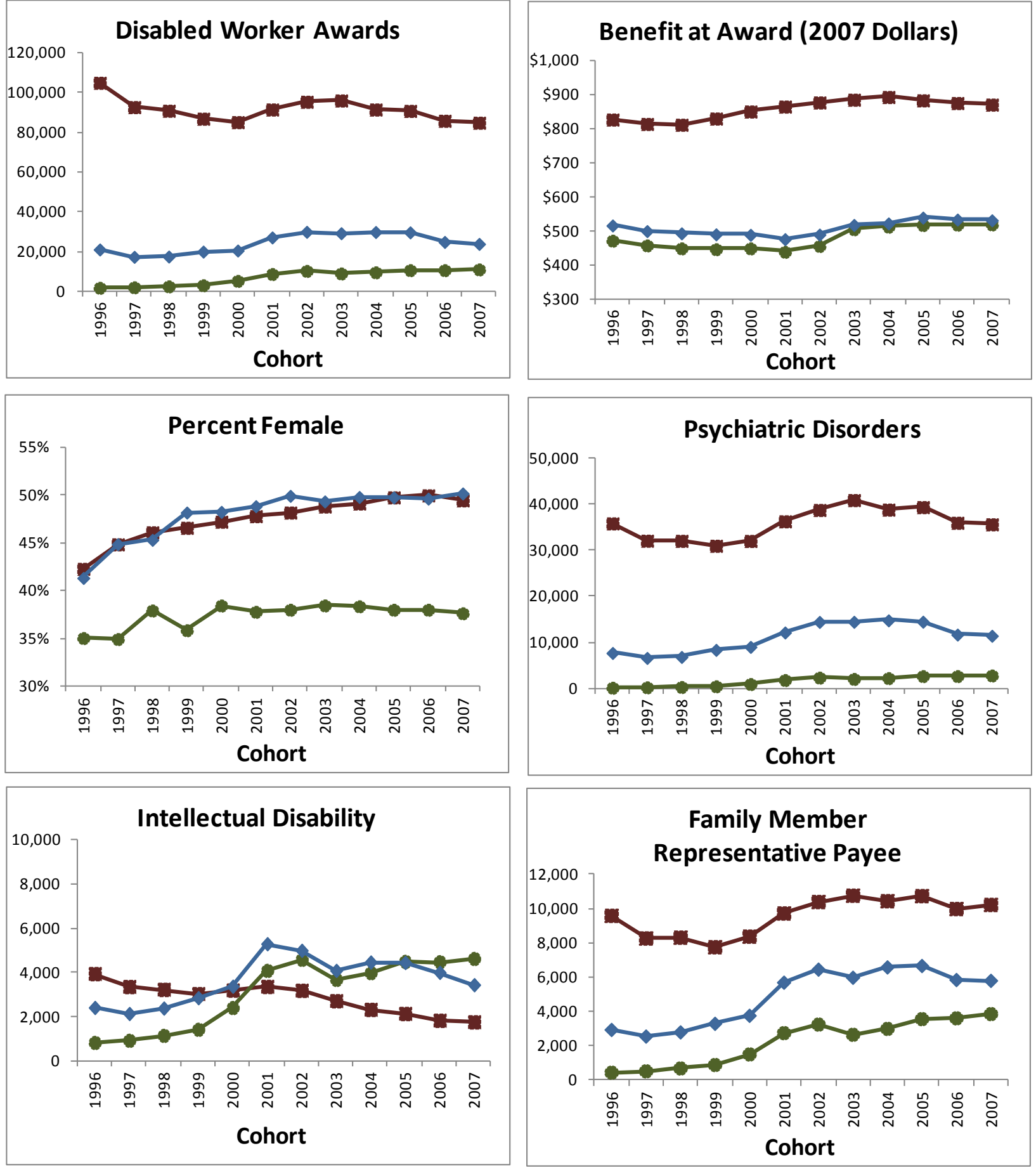

$$
\begin{aligned}
& - \text { Disabled Worker, No SSI } \\
& - \text { Disabled Worker, SSI as Child } \\
& - \text { Disabled Worker, SSI as Adult Only }
\end{aligned}
$$

Note: $\quad$ Based on analysis of OASDI beneficiary records in 2009 DAF. 


\section{Psychiatric Disorders}

The percentage of disabled worker awardees with psychiatric disorders is substantially higher among those with no SSI history as children than among those with SSI history as children (see Appendix Table A.4 for percentages). As seen in the middle right panel of Figure V.1, fluctuations in the number of beneficiaries with psychiatric disorders largely resemble fluctuations in the overall subgroup sizes (top left panel). The percentage with psychiatric disorders rose steadily from 1996 to 2003 for all three subgroups, however, and continued to rise through 2007 for those with SSI history as children.

\section{Intellectual Disability}

The percentage of disabled worker awardees with intellectual disability is the highest, by far, among those who received SSI as children (see Appendix Table A.4 for percentages). As seen in the bottom left panel of Figure V.1, the number of those with both intellectual disability and SSI history increased substantially from the late 1990s through 2001, after which the increase was fairly steady. In contrast, the number of awardees with intellectual disability among those with no SSI history declined throughout most of the period, with a temporary lull from 1999 to 2002.

\section{Family Member Representative Payee}

Finally, the percentage of awardees with a family member representative payee, which is highest among disabled workers who were on SSI as children, has been rising consistently for all three groups (see Appendix Table A.4 for percentages). As seen in the bottom right panel of Figure V.1, for those with no SSI history, changes in the number of awardees with a family member representative payee roughly follow the trend in that group for psychiatric disorders. For those who received SSI first, however, changes in the number of awardees with a family member representative payee appear to reflect the trends for intellectual disability.

\section{B. Trends for DAC}

In Figure V.2, we show trends for selected characteristics of young DAC awardees, by subgroup. ${ }^{12}$ Once again, counts by subgroup are in the top left panel to facilitate comparison of trends across characteristics. Notably, the number of DAC awardees who received SSI as children steadily increased throughout the period. In addition, we observe, between 2001 and 2003, an apparent one-to-one substitution between the number of awardees with no SSI history and the number with SSI history as adults only. The shift suggests that a substantial share of DAC awardees who would not have had SSI history at the time of DAC award if that award were made in 2001 or earlier did have such a history when they applied in 2002 or later.

\footnotetext{
${ }^{12}$ See Appendix Tables A.3 and A.4 for detailed counts and percentages, respectively. See Appendix Table A.5 for the mean benefit at award.
} 
Figure V.2. Selected Cohort Trends for Young DAC Awardees, by Subgroup, 1996-2007
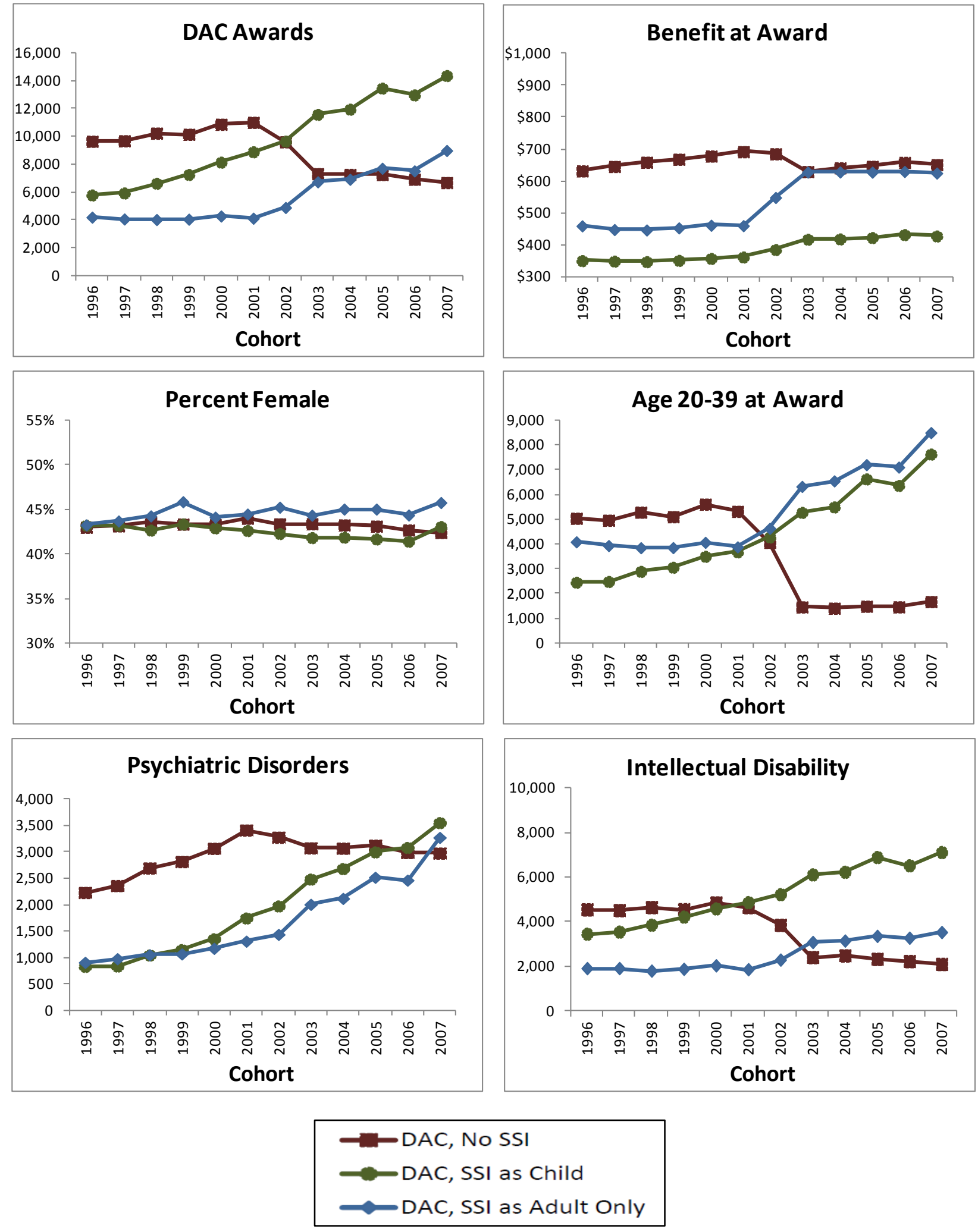

Note: $\quad$ Based on analysis of OASDI beneficiary records in 2009 DAF. 


\section{Mean Benefit at Award}

The mean benefit at award is lowest for DAC who received SSI as children (top right panel). For this subgroup, the mean benefit at award remained steady at around \$350 (in 2007 dollars) from 1996 to 1999 and then increased to just under $\$ 420$ by 2003 , after which it remained fairly stable. For those with no SSI history, the mean benefit at award increased steadily from $\$ 633$ in 1996 to $\$ 693$ in 2001 and then dropped to $\$ 632$ in 2003 , after which it hovered around $\$ 650$. For those who received SSI as adults only, the mean benefit at award was steady from 1996 to 2001 at around $\$ 460$ and then jumped to $\$ 629$ (an almost 40 percent increase) in 2003, after which it remained stable. These trends suggest that, in later cohorts, DAC awardees who had received SSI were less disadvantaged than those awarded DAC benefits earlier in the study period, especially those with SSI history as adults only. Given that DAC benefits are a function of the beneficiary's parent's benefit amount, the trend suggests that, after 2001, especially among those with SSI history as adults only, DAC awardees came from families that were on average financially better off than DAC in the same subgroup who were awarded benefits in 2001 or earlier.

\section{Percent Female}

In contrast to disabled worker awardees, the percentage of DAC awardees who were female was similar for all three subgroups at about 43 percent and remained fairly steady from 1996 to 2007 (middle left panel).

\section{Age at Award}

Between 40 and 50 percent of young DAC awardees in each cohort were age 18 or 19 when they first received DI benefits; the remaining 50 to 60 percent were age 20 to 39 (see Appendix Table A.4 for percentages). The one-to-one substitution between awardees with no SSI history and awardees with SSI history as adults only is evident among DAC awardees age 20 to 39 , as seen in the middle right panel of Figure V.2. While the number of awardees who had received SSI as children rose continuously throughout the period, the numbers for the two groups of DAC awardees who had not been SSI recipients as children remained stable from 1996 to 2001 and then moved in opposite directions between 2001 and 2003. From 2003 onward, the number of new awardees age 20 to 39 with no SSI history remained stable (and low), and the number of awardees who were SSI recipients as adults only rose almost in lockstep with the number who had received SSI as children.

\section{Impairment Types}

As with disabled workers, the percentage of DAC awardees with psychiatric disorders is substantially higher among those with no SSI history as children than among those who received SSI as children. In contrast, the percentage of DAC with intellectual disability is substantially higher among those with SSI history as children (see Appendix Table A.4 for percentages). The trends in the number of awardees with these impairments, seen in the bottom two panels of Figure V.2, appear to be consistent with the one-to-one substitution of those with no SSI history with those who received SSI as adults only. The number of new DAC awardees with psychiatric disorders among those with no SSI history levels off as of 2001, and the same number among those with adult-only SSI history starts to rise quickly. Similarly, the number of new DAC awardees with intellectual disability among those with no SSI history starts to fall in 2001; the same number among those with adult-only SSI history begins to rise. 
Page is intentionally left blank to allow for double-sided copying 


\section{TRENDS IN LONGITUDINAL OUTCOMES FOR THE 1996-2004 AWARD COHORTS}

To assess how more recent cohorts have fared relative to earlier ones, we compare statistics for key outcomes by the end of the fifth post-award year across annual award cohorts. Once more, even though new DAC awards represent a minority of new SSD awards to individuals under age 40, we show trends in outcomes separately for DAC because their share of awards has been steadily increasing and little is known about outcomes for this group. Accounting for the five-year follow-up period, the comparison includes nine award cohorts, beginning with the 1996 cohort and ending with the 2004 cohort. In the figures below, we show comparisons across the nine award cohorts, with the award year on the horizontal axis and outcome measure on the vertical axis. The observed trends reflect changes in the composition of personal characteristics as well as the effects of changes in SSA policies, policies external to SSA, or the economic environment. In the next section, we discuss potential explanations for these trends.

\section{A. Trends for Disabled Workers}

\section{Mortality}

In Figure VI.1, we show trends in outcomes for young disabled worker awardees. ${ }^{13}$ Cumulative mortality is lowest for those who received SSI as children, presumably in large part because they are younger on average than the two other groups of disabled workers (top left panel). Mortality has fallen for all three subgroups since the 1996 award cohort - especially for those who received SSI only as adults. Among new disabled worker awardees with no SSI history, the trend in falling cumulative mortality is reversed somewhat for the period between 1998 and 2000. Among those who received SSI as children, however, the decline in cumulative mortality is most noticeable during that period. Among those who received SSI benefits as adults only, the decrease in cumulative mortality appears to end with the 2002 cohort.

\section{SSI Payments}

As expected, annual SSI payment percentages in the fifth post-award year are highest among those who received SSI benefits before they were awarded disabled worker benefits (bottom left panel). Nevertheless, a substantial share of those who received SSI first as children or adults leave SSI in the first five years. Some might be deceased, but perhaps others no longer need (or qualify for) SSI and Medicaid because they receive DI benefits and (after the waiting period) qualify for Medicare. Notably, the annual SSI percentages fall precipitously for the two groups with SSI history after the 2001 cohort. In addition, roughly 10 percent of those with no SSI history received an SSI payment in the fifth post-award year.

\footnotetext{
${ }^{13}$ See Appendix Table A.6 for the percentages by cohort and subgroup.
} 
Figure VI.1. Trends in Outcomes in Fifth Post-Award Year, Young Disabled Worker Awardees, by Subgroup and Cohort, 1996-2004


Note: $\quad$ Based on analysis of OASDI beneficiary records in 2009 DAF matched with MEF data. 


\section{STW and NSTW Months}

In the top middle and right panels of Figure VI.1, we show trends in, respectively, the cumulative percentage achieving DI STW in at least one month and the cumulative number of DI NSTW months per 1,000 awardees. The cumulative DI STW percentage is highest among disabled workers who received SSI as children. The cumulative DI STW percentages are substantially lower among those with no SSI history (falling since the late 1990s) or those who received SSI only as adults (fairly constant at about 10 percent since 1996). The trends for DI NSTW months track the trends for the DI STW percentage, with former SSI children accumulating the most time in DI NSTW. To illustrate these statistics further, for former SSI children first awarded disabled worker benefits in 2001, we find that 5.1 percent of the months from DI award through December 2006 were DI NSTW months; the respective numbers are 3.3 percent for those with no SSI history and 2.6 percent for those who received SSI as adults only.

\section{Annual Earnings}

Many more young disabled workers are employed and earn more than $\$ 1,000$ (in 2007 dollars) annually according to MEF data than achieve DI STW (bottom middle panel of Figure VI.1). As with DI STW, the cumulative percentages employed and earning more than $\$ 1,000$ annually are highest for disabled workers who received SSI as children; by the end of 2001, 72 percent of former SSI children in the 1996 cohort had earned at least $\$ 1,000$ in at least one year compared with roughly 40 percent for the two groups that did not receive SSI as children. Once more, the cumulative percentage moves downward for disabled workers with no SSI history and remains fairly steady for those who received SSI as adults only; it also falls for former SSI children-especially after the 1999 cohort. Finally, former SSI children also have the highest cumulative percentages with annual earnings above 12 times SGA for that year (bottom right panel of Figure VI.1). For those who did not receive SSI as children, the trends for this percentage are similar to the trends for the percentage earning at least $\$ 1,000$. For former SSI children, however, the percentage drops substantially from the 1996 cohort to the 1998 cohort.

\section{B. Trends for DAC}

\section{Mortality}

In Figure VI.2, we show trends in outcomes for young DAC awardees. ${ }^{14}$ Cumulative mortality among young DAC awardees is generally lower than that among young disabled worker awardees (top left panel). Among the 1996 cohort, DAC awardees with no SSI history had the lowest mortality rates, whereas those with an SSI history as adults only had the highest mortality rates. Notably, cumulative mortality has risen since 1996 among DAC with no SSI history and has fallen for those who received SSI - especially among those who received benefits as adults only.

\footnotetext{
${ }^{14}$ See Appendix Table A.6 for the percentages by cohort and subgroup.
} 
Figure VI.2. Trends in Outcomes in Fifth Post-Award Year, Young DAC Awardees, by Subgroup and Cohort, 1996-2004
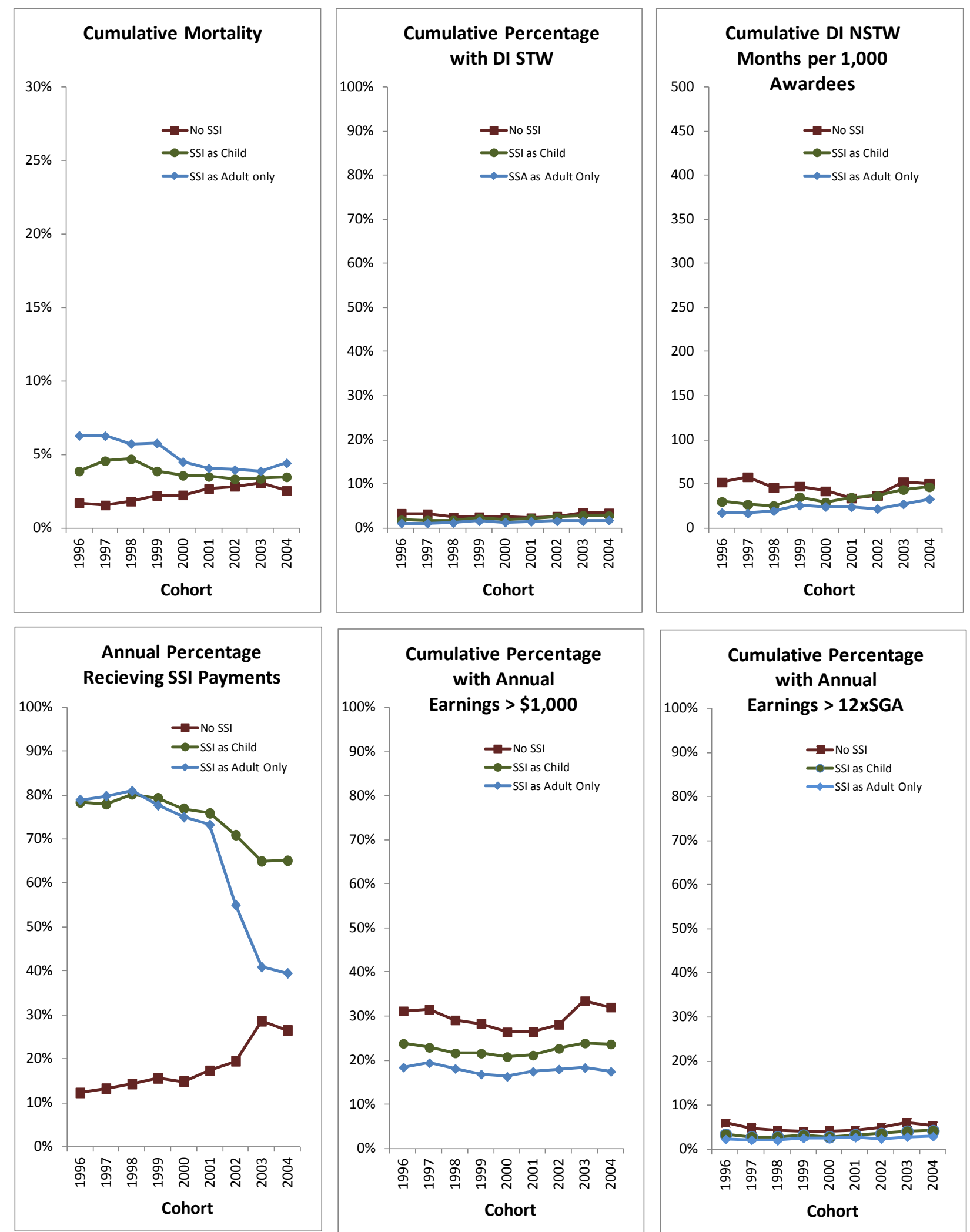

Note: $\quad$ Based on analysis of OASDI beneficiary records in 2009 DAF matched with MEF data. 


\section{SSI Payments}

Annual SSI payment percentages in the fifth post-award year are highest among DAC who received SSI benefits before they were awarded DAC benefits (bottom left panel of Figure VI.2). For those DAC, the annual SSI percentages generally fall after the 1998 cohort, especially between the 2001 and 2003 cohorts. Around 10 percent of DAC with no SSI history in the 1996 cohort received an SSI payment in the fifth year after the award of DAC benefits. This percentage tripled to close to 30 percent for the 2003 cohort, with most of that increase occurring between the 2000 and 2003 cohorts. It is notable that a substantial share of DAC who first received SSI leave SSI in the first five years. As with disabled workers, some DAC might be deceased, and others might no longer need (or qualify for) SSI and Medicaid because they receive DI benefits and (after the waiting period) qualify for Medicare.

\section{STW and NSTW Months}

The percentage achieving DI STW is much lower for all three DAC groups than for disabled workers and is highest among DAC with no SSI history (top middle panel of Figure VI.2). On average, DAC not previously on SSI also accumulated the most time in DI NSTW (top right panel). For those with no SSI history and first awarded DAC benefits in 2001, we find that 0.6 percent of the months from DI award through December 2006 were DI NSTW months; the respective numbers are 0.6 percent for those who received SSI as children and 0.4 percent for those who received SSI as adults only. The percentages are substantially lower among DAC than among disabled workers.

\section{Annual Earnings}

According to MEF data, many more young DAC are employed and earn more than $\$ 1,000$ (in 2007 dollars) annually than achieve DI STW (bottom middle panel). The cumulative percentages earning more than $\$ 1,000$ annually are highest for DAC with no SSI history; by 2001, 31 percent of this group in the 1996 cohort had earned more than $\$ 1,000$ annually in at least one year compared with about 24 percent of those who received SSI as children and 18 percent of those who received SSI as adults only. DAC with no SSI history also have the highest cumulative percentages with annual earnings above 12 times SGA for that year (bottom right panel). For all three DAC groups, the trends for this percentage are similar to the trends for the percentage employed and earning at least $\$ 1,000$ annually, though at much lower levels. 
Page is intentionally left blank to allow for double-sided copying 


\section{DISCUSSION}

In this study, we examined, from a longitudinal perspective, trends in the characteristics and outcomes of young SSD awardees. Many young SSD awardees will be on the rolls for decades, receive Medicare during most of that time, and rarely participate in the labor force. Policies to help young adults with disabilities lead more productive, fulfilling lives and reduce their dependence on government support are therefore of great interest, but much remains unknown about the impact of current policies on programmatic and employment outcomes.

We found substantial compositional changes among young SSD awardees during the study period, with important implications for policies intended to serve the population in the years ahead. In 2007, compared to 1996 , relatively more SSD awards to individuals below age 40 went to DAC versus disabled workers; to disabled workers and DAC who had received SSI benefits, especially as children, versus those with no SSI history; and to disabled workers and DAC with psychiatric disorders versus those with other types of impairments. Increasingly, young SSD awardees had a family member as representative payee.

Most of the fluctuation in the annual number of young SSD awardees reflects changes in the number of awards to disabled workers - a number that reached its peak in 2002 and 2003 after the recession of 2001 and that likely was surpassed during the recent Great Recession. In contrast, the number of DAC awards climbed steadily from 1996 to 2007 , an increase that is largely accounted for by an increase in the number of DAC who had received SSI benefits as children.

Our findings also suggest that, from 2002 onward, many DAC received SSI as adults before they started receiving DAC benefits, whereas they might not have done so before 2002. In what is likely a related trend, the mean benefit at award among DAC who began receiving SSI only in adulthood increased substantially from 2001 to 2003 . With DAC benefits tied to a beneficiary's parent's lifetime earnings, the latter finding indicates that, after 2001, DAC awardees who received SSI for the first time as adults had parents who were on average financially better off than DAC in the same subgroup who were awarded DAC benefits in 2001 or earlier.

Finally, our analysis of outcomes as of the fifth post-award year reveals some interesting trends and important differences across subgroups. Substantial shares of beneficiaries who received SSI first, as either children or adults, leave SSI in the first five years after SSD award, especially if they were first awarded disabled worker or DAC benefits after 2001. We also found that disabled workers who received SSI as children are far more likely than those who did not receive SSI as children to earn more than $\$ 1,000$ (in 2007 dollars) annually as of the fifth post-award year; that compared to disabled workers, DAC are considerably less likely to work and earn more than $\$ 1,000$ annually; and that both disabled workers and DAC are significantly less likely to earn more than 12 times SGA annually than they are to earn more than $\$ 1,000$ annually. Further, disabled workers in later cohorts were less likely than disabled workers in earlier cohorts to achieve these milestones.

Several factors have potentially contributed to the observed trends - most notably the compositional changes in terms of awards to disabled workers versus DAC, awards to increasingly more individuals with an SSI history, awards to increasingly more females, and awards to increasingly more individuals with psychiatric disorders. It is difficult to distinguish between the effects of the various factors, however, because of the overlap in timing. We consider several such factors below. 


\section{A. Potential Factors}

\section{Growth in Child SSI Program}

The number of children receiving SSI benefits more than tripled from 1989 through 1995; from 2000 through 2009, the number expanded by another 40 percent (Wittenburg 2011). Following the 1990 Supreme Court decision in Sullivan v. Zebley, SSI eligibility determination for children became less restrictive and included assessments of the child's ability to function in a manner appropriate to his or her age (Coe and Rutledge 2013). The Zebley decision led to a significant increase in the number of children age 5 to 12 who received SSI benefits (SSA 2006b). The eldest of these children would have turned 18 by the end of the 1990s and would have needed as few as six QCs to qualify for disabled worker benefits and no QCs to qualify for DAC benefits if an OASDI-eligible parent retired, died, or began receiving DI benefits. The fact that growth in SSD awards among those who were on SSI as children is the largest source of growth in SSD award suggests a causal relationship, but it is possible that most of these individuals would have entered SSD as young adults even if they had not entered SSI as children. The fact that the Zebley decision pertained mostly to psychiatric disorders related to behavioral problems, coupled with the increase in awardees with psychiatric disorders, also is consistent with the hypothesis that Zebley eventually led to an increase in SSD awards, but again is not definitive. The Zebley decision likely also had a spillover effect on poor young adults-perhaps unmarried mothers in particular. Following the decision, when disability advocates and state welfare agencies learned that some children were now eligible for SSI because of psychiatric disorders, they figured out that some parents were likely eligible, too (Rupp and Stapleton 1998). As discussed below, the 1996 welfare reform probably contributed further to the increase in child SSI cases.

\section{Welfare Reform}

Following the 1996 reform of welfare benefits for low-income families with children, states had a stronger incentive to help parents with disabilities in low-income families obtain either SSI or DI benefits (Stapleton et al. 2002). ${ }^{15}$ There was always an incentive for states to help those receiving SSI to obtain DI, because they could shift health care costs from Medicaid - a federal-state program - to Medicare - an all-federal program. As the cost of health care escalated, the incentive took on greater value. In addition, given that SSI benefits are generally more generous than TANF benefits and do not impose work requirements or time limits, low-income mothers of children with a disability have a financial incentive to apply to SSI rather than to TANF (Wittenburg 2011); as shown by Wiseman (2011), the incentive has increased over time. The trends in the wake of welfare reform likely played a major role in the observed increase in the percentage of females among new disabled worker awardees with an SSI history-almost all of which occurred in the period from 1996 to 2002-as well as in the general increase in SSD awardees with an SSI history.

\section{Special Disability Workload}

Studies conducted by SSA in 1999, 2002, and 2004 identified over 460,000 cases of SSI beneficiaries who potentially were DI insured, based on their earnings (SSA 2006a). Consequentially, many SSI beneficiaries, known as special disability workload (SDW) cases, were awarded DI payments retroactively. Some of the observed trends for new SSD awardees who first received SSI may therefore

\footnotetext{
${ }^{15}$ As recently highlighted on NPR's Planet Money program, some states pay private companies to help move individuals on their welfare rolls into federal disability programs (Joffe-Walt 2013).
} 
reflect SSA's efforts to process the SDW cases; as noted by Zayatz (2005), many SSI recipients who were awarded DI benefits were under age 35 and were eligible for SSI because of a psychiatric disorder.

\section{Demographic Trends}

The steady increase in DAC awards throughout the study period is likely related to the aging of the baby boomers. The earliest baby boomers turned 50 in 1996; at that age, it would be easier to qualify for disabled worker benefits and, consequentially, for their children to qualify for DAC benefits. Indeed, Liu and Stapleton (2011) document an increase in DI awards to beneficiaries age 50 and older throughout the same period. In addition, the observed decrease in mortality rates among young disabled worker awardees might be attributable to increases in longevity as well as to compositional changes among new awardees. For example, the increases in both the percentage of awardees who were female and the percentage with psychiatric disorders might have had positive effects on mortality. Indeed, the increases in both percentages come to an end at around the same time that the decline in mortality ends for the group of disabled workers who received SSI as adults only. However, the mean age at award also fell somewhat during those years, which likely reduced mortality.

\section{Recession of 2001}

The 2001 recession likely induced applications for disabled worker benefits among individuals with or without an SSI history. These effects are most noticeable in the increase in the number of new disabled worker beneficiaries between 2000 and 2002 for all three subgroups. Further, by inducing both early retirement and applications for disabled worker benefits among primary OASDI beneficiaries, the recession might have also increased the number of DAC awards. To the extent that the 2001 recession was associated with increased DI entry of those with relatively less severe disabilities, higher historical earnings, or a higher propensity to work (Ben-Shalom and Mamun 2013), the recession might have also played a role in the observed decrease in the percentage on SSI in the fifth year post-award among later SSD cohorts.

\section{SGA Increase in 1999}

In July 1999, the SGA threshold increased from $\$ 500$ to $\$ 700$. In theory, the increase should have induced the submission of SSD applications among those at the margin (Schimmel et al. 2011; Maestas et al. 2012). Maestas and colleagues estimate that the increased threshold induced a 4.7 percent increase in applications. It is safe to assume that some of the newly induced applications were rejected; among the individuals awarded SSD, however, some probably have relatively less severe impairments and come from more advantaged backgrounds, on average, than those who entered SSD before the increase in the SGA threshold. In addition, the SGA increase could have induced entry into adult SSI by future DAC awardees who previously would have not applied for SSI; such an effect would be consistent with the observed increase, starting in 2001, in the percentage of DAC receiving SSI as adults before they received DAC benefits. Further, if relatively high-income parents were more likely than others to use the SGA increase opportunistically for their disabled children, they would account for the increase in mean benefit at award for DAC who first received SSI as adults. The SGA increase also likely explains, at least in part, why new disabled worker awardees in later cohorts were less likely to earn more than 12 times the non-blind SGA amount - the threshold itself increased.

\section{B. Additional Research}

We have documented trends in the composition, characteristics, and outcomes of the young adult population first awarded SSD benefits in 1996 to 2007 and consider factors that might account for the observed trends. Our findings raise many more questions than they answer, however. Questions for future research include the following: To what extent did the Zebley decision and welfare reform contribute to 
growth in the number of young SSD awardees? How much, if at all, has growth in longevity contributed to overall growth in the number of SSD beneficiaries? In what ways do families provide for young SSD awardees? How do DAC awards affect the well-being of DAC and their families, and what happens when both parents die before the DAC? Looking ahead, what should we expect for DAC awards as the baby boomers increasingly receive OASDI benefits? How did the Great Recession affect the number of young SSD awardees? Research focused on these and related questions will improve our understanding of the reasons behind changes in the composition of SSD awardees and the implications for disability policy.

\section{Policy Issues}

Our findings raise several policy issues. Most important, policymakers need to consider other options for the support of youth and young adults with disabilities - options that do not discourage work while promoting dependence. For example, rigorous evidence shows that employment supports can help young adults with disabilities achieve some employment success. Two prominent examples are the Mental Health Treatment Study (Frey et al. 2011) and the Youth Transition Demonstration (Fraker 2013). Any consideration of policies that affect the work options and self-sufficiency prospects for youth and young adults with disabilities should carefully account for the observed changes to the young SSD population, which increasingly includes more females, more DAC, more beneficiaries with an SSI history, and more beneficiaries with psychiatric disorders. These compositional changes also have implications for Medicare because the mix of health care services used by young SSD awardees, most of whom qualify for Medicare after a 24-month waiting period, likely differs today (and even more so over the long term) from a decade ago. Another issue is whether states will continue to face increasingly strong financial incentives to help people receiving SSI to obtain DI - and eventually Medicare - as the cost of health care continues to escalate, placing growing pressure on state Medicaid budgets.

Furthermore, policymakers might want to consider whether it continues to make sense to tie support for DAC to the retirement, death, or disability of a parent. Under current policy, two young adults who experienced onset of the same disabling condition before age 22 could face vastly different lifetime prospects in terms of cash and medical benefits if one of them qualifies for DAC benefits tied to a parent's lifetime earnings and the other qualifies only for SSI. In addition, a young adult disabled before age 22 whose parent died, retired, or qualified for DI benefits will qualify for DAC and Medicare benefits, but another young adult with the same disability whose parents are alive and not receiving SSA retirement or disability benefits will not qualify for DAC or Medicare benefits, and the parents will not necessarily provide them with income support and, especially, health insurance. For these individuals, such differences in cash and medical benefits received during a lifetime of disability will most likely result in vastly different outcomes across a range of domains. 


\section{REFERENCES}

Ben-Shalom, Yonatan, and Arif Mamun. "Return-to-Work Outcomes Among Social Security Disability Insurance Program Beneficiaries." Washington, DC: Mathematica Policy Research, 2013.

Berkowitz, Edward D. Statement before the Subcommittee on Social Security, Committee on Ways and Means, U.S. House of Representatives, Washington, DC, July 13, 2000.

Burkhauser, Richard V., and Mary C. Daly. "The Returns to Work for Children Leaving the SSIDisabled Children Program." RAND Working Paper No. WR-802-SSA. Santa Monica, CA: RAND Corporation, 2010.

Coe, Norma B., and Matthew S. Rutledge. "What Is the Long-Term Impact of Zebley on Adult and Child Outcomes?" Working Paper No. 2013-3. Chestnut Hill, MA: Boston College Center for Retirement Research, 2013.

Congressional Budget Office (CBO). Policy Options for the Social Security Disability Insurance Program. Washington, DC: CBO, 2012.

Fraker, Thomas. "The Youth Transition Demonstration: Lifting Employment Barriers for Youth with Disabilities." Issue Brief No. 13-01. Washington, DC: Center for Studying Disability Policy, February 2013.

Fraker, Thomas, and Todd Honeycutt. "Promoting Readiness of Minors in Supplemental Security Income (PROMISE): Recommendations of the Technical Advisory Panel Regarding the Use of Incentive Payments and the Evaluation Design." Washington, DC: Mathematica Policy Research, February 2012.

Fraker, Thomas, and Anu Rangarajan. "The Social Security Administration's Youth Transition Demonstration Projects." Journal of Vocational Rehabilitation, vol. 30, no. 3, 2009, pp. 223240.

Frey, William D., Robert E. Drake, Gary R. Bond, Alexander L. Miller, Howard H. Goldman, and David S. Salkever. "Mental Health Treatment Study: Final Report." Rockville, MD: Westat, July 2011.

Gates, Gordon. "Disabled Adult Child (DAC) Benefits." Social Security Disability Lawyer Blog. Available at [http://www.socialsecuritydisabilitylawyer.us/blog/2011/08/disabled-adult-childdac-benefits.html]. Accessed October 18, 2012.

Goss, Stephen C. Statement before the Subcommittee on Social Security, Committee on Ways and Means, U.S. House of Representatives, Washington, DC, March 14, 2013.

Joffe-Walt, Chana. "Unfit for Work: The Startling Rise of Disability in America." Available at [http://apps.npr.org/unfit-for-work/]. Accessed May 15, 2013.

Liu, Su, and David C. Stapleton. "Longitudinal Statistics on Work Activity and Use of Employment Supports for New Social Security Disability Insurance Beneficiaries." Social Security Bulletin, vol. 71, no. 3, 2011, pp. 35-60.

Livermore, Gina, David Stapleton, and Allison Roche. "Characteristics, Employment, and Sources of Support Among Working-Age SSI and DI Beneficiaries." Report No. 2. In Work Activity and Use of Employment Supports under the Original Ticket to Work Regulations. Washington, DC: Mathematica Policy Research, 2009. 
Maestas, Nicole, Kathleen Mullen, and Gema Zamarro. "Induced Entry into the Social Security Disability Program: Using Past SGA Changes as a Natural Experiment." Working Paper No. 2012-262. Ann Arbor, MI: Michigan Retirement Research Center, 2012.

Mamun, Arif A., Paul O'Leary, David C. Wittenburg, and Jesse Gregory. "Employment Among Social Security Disability Program Beneficiaries, 1996-2007." Social Security Bulletin, vol. 71, no. 3, 2011, pp. 11-34.

Rupp, Kalman, and David C. Stapleton, eds. Growth in Disability Benefits: Explanations and Policy Implications. Kalamazoo, MI: W.E. Upjohn Institute for Employment Research, 1998.

Schimmel, Jody, David C. Stapleton, and Jae Song. "How Common Is 'Parking' Among Social Security Disability Insurance (SSDI) Beneficiaries? Evidence from the 1999 Change in the Level of Substantial Gainful Activity (SGA)." Social Security Bulletin, vol. 71, no. 4, 2011, pp. 77-92.

She, Peiyun, and Gina A. Livermore. "Long-Term Poverty and Disability Among Working-Age Adults." Journal of Disability Policy Studies, vol. 19, no. 4, 2009, p. 244-256.

Social Security Administration (SSA). "Annual Statistical Report on the Social Security Disability Insurance Program, 2010." Baltimore, MD: SSA, 2011.

Social Security Administration (SSA). "The Social Security Administration's Identification of Special Disability Workload Cases." Baltimore, MD: SSA, Office of the Inspector General, 2006a.

Social Security Administration (SSA). "Trends in the Social Security and Supplemental Security Income Disability Programs." Washington, DC: SSA, $2006 \mathrm{~b}$.

Social Security and Medicare Boards of Trustees. "A Summary of the 2012 Annual Reports: Social Security and Medicare Boards of Trustees." Baltimore, MD: Social Security Administration, 2012.

Stapleton, David C., David C. Wittenburg, Michael E. Fishman, and Gina A. Livermore. "Transitions from AFDC to SSI Before Welfare Reform." Social Security Bulletin, vol. 64, no. 1, 2002, pp. 84-114.

Wiseman, Michael. "Supplemental Security Income for the Second Decade." Poverty \& Public Policy, vol. 3, no. 1, 2011, pp. 1-18.

Wittenburg, David. Statement before the Subcommittee on Human Resources, Committee on Ways and Means, U.S. House of Representatives, Washington, DC, October 27, 2011.

Zayatz, Tim. "Social Security Disability Insurance Program Worker Experience." Actuarial Study No. 118, Baltimore, MD: Social Security Administration, Office of the Chief Actuary, 2005. 
APPENDIX TABLES 
Page is intentionally left blank to allow for double-sided copying 
Table A.1. Description of Longitudinal Outcomes Measured as of Five Years After Award Year

\begin{tabular}{|c|c|}
\hline Longitudinal Outcome & Description \\
\hline Cumulative Mortality & $\begin{array}{l}\text { Percentage of SSD awardees who died as of the end of the fifth post-award } \\
\text { year. }\end{array}$ \\
\hline Annual Percentage Receiving SSI Payments & $\begin{array}{l}\text { Percentage of SSD awardees who received SSI benefits in at least one } \\
\text { month in the fifth post-award year. }\end{array}$ \\
\hline Cumulative Percentage with DI STW & $\begin{array}{l}\text { Percentage of SSD awardees whose earnings exceeded SGA in at least one } \\
\text { month during or after the Extended Period of Eligibility (EPE) and before the } \\
\text { end of the fifth post-award year. }\end{array}$ \\
\hline $\begin{array}{l}\text { Cumulative DI STW Months per 1,000 } \\
\text { Awardees }\end{array}$ & $\begin{array}{l}\text { The number of months in which an SSD awardee received no SSD } \\
\text { payments following benefit suspension or termination because of work and } \\
\text { before he or she died or reached the end of the fifth post-award year, per } \\
1,000 \text { awardees. }\end{array}$ \\
\hline $\begin{array}{l}\text { Cumulative Percentage with Annual Earnings } \\
>\$ 1,000 \text { (in } 2007 \text { dollars) }\end{array}$ & $\begin{array}{l}\text { Percentage of SSD awardees with annual earnings of at least } \$ 1,000 \text { in } \\
2007 \text { dollars based on MEF data, starting with the second full calendar year } \\
\text { after the award year and ending with the fifth post-award year. We start with } \\
\text { the second full calendar year after award so that the statistics do not include } \\
\text { those with carried-over earnings from pre-award jobs, but with no } \\
\text { subsequent earnings. }\end{array}$ \\
\hline $\begin{array}{l}\text { Cumulative Percentage with Annual Earnings } \\
>12 \times \text { SGA }\end{array}$ & $\begin{array}{l}\text { Percentage of SSD awardees with annual earnings of at least } 12 \text { times the } \\
\text { non-blind SGA based on MEF data, starting with the second full calendar } \\
\text { year after the award year and ending with the fifth post-award year. We start } \\
\text { with the second full calendar year after award such that the statistics do not } \\
\text { include those with carried-over earnings from pre-award jobs, but with no } \\
\text { subsequent earnings. }\end{array}$ \\
\hline
\end{tabular}


Table A.2. SSD Award Groups, Age 18-39, by Year of First Award

\begin{tabular}{|c|c|c|c|c|c|c|c|c|c|c|c|c|}
\hline SSD Award Year & 1996 & 1997 & 1998 & 1999 & 2000 & 2001 & 2002 & 2003 & 2004 & 2005 & 2006 & 2007 \\
\hline & \multicolumn{12}{|c|}{ Counts } \\
\hline Total & 148,242 & 132,513 & 132,484 & 132,045 & 134,906 & 152,038 & 160,523 & 160,737 & 157,880 & 160,619 & 150,350 & 153,020 \\
\hline Disabled Worker & 127,669 & 112,009 & 110,809 & 109,842 & 110,840 & 127,209 & 135,477 & 134,132 & 130,778 & 131,009 & 121,228 & 119,635 \\
\hline Disabled Worker, No SSI & 104,783 & 92,577 & 90,755 & 86,755 & 85,020 & 91,367 & 95,255 & 95,894 & 91,361 & 90,673 & 85,707 & 84,733 \\
\hline Disabled Worker, SSI as Child & 1,810 & 2,056 & 2,527 & 3,080 & 5,269 & 8,718 & 10,284 & 8,996 & 9,572 & 10,669 & 10,658 & 11,031 \\
\hline Disabled Worker, SSI as Adult & 21,076 & 17,376 & 17,527 & 20,007 & 20,551 & 27,124 & 29,938 & 29,242 & 29,845 & 29,667 & 24,863 & 23,871 \\
\hline DAC & 19,626 & 19,670 & 20,874 & 21,449 & 23,275 & 24,001 & 24,137 & 25,613 & 26,111 & 28,409 & 27,394 & 30,003 \\
\hline DAC, No SSI & 9,642 & 9,674 & 10,222 & 10,140 & 10,858 & 10,997 & 9,600 & 7,316 & 7,262 & 7,257 & 6,920 & 6,677 \\
\hline DAC, SSI as Child & 5,785 & 5,928 & 6,625 & 7,256 & 8,137 & 8,881 & 9,646 & 11,566 & 11,936 & 13,448 & 12,959 & 14,347 \\
\hline DAC, SSI as Adult & 4,199 & 4,068 & 4,027 & 4,053 & 4,280 & 4,123 & 4,891 & 6,731 & 6,913 & 7,704 & 7,515 & 8,979 \\
\hline \multirow[t]{2}{*}{ Unclassified } & 947 & 834 & 801 & 754 & 791 & 828 & 909 & 992 & 991 & 1,201 & 1,728 & 3,382 \\
\hline & \multicolumn{12}{|c|}{ Percentages } \\
\hline Total & 100.0 & 100.0 & 100.0 & 100.0 & 100.0 & 100.0 & 100.0 & 100.0 & 100.0 & 100.0 & 100.0 & 100.0 \\
\hline Disabled Worker & 86.1 & 84.5 & 83.6 & 83.2 & 82.2 & 83.7 & 84.4 & 83.4 & 82.8 & 81.6 & 80.6 & 78.2 \\
\hline Disabled Worker, No SSI & 82.1 & 82.7 & 81.9 & 79.0 & 76.7 & 71.8 & 70.3 & 71.5 & 69.9 & 69.2 & 70.7 & 70.8 \\
\hline Disabled Worker, SSI as Child & 1.4 & 1.8 & 2.3 & 2.8 & 4.8 & 6.9 & 7.6 & 6.7 & 7.3 & 8.1 & 8.8 & 9.2 \\
\hline Disabled Worker, SSI as Adult & 16.5 & 15.5 & 15.8 & 18.2 & 18.5 & 21.3 & 22.1 & 21.8 & 22.8 & 22.6 & 20.5 & 20.0 \\
\hline DAC & 13.2 & 14.8 & 15.8 & 16.2 & 17.3 & 15.8 & 15.0 & 15.9 & 16.5 & 17.7 & 18.2 & 19.6 \\
\hline DAC, No SSI & 49.1 & 49.2 & 49.0 & 47.3 & 46.7 & 45.8 & 39.8 & 28.6 & 27.8 & 25.5 & 25.3 & 22.3 \\
\hline DAC, SSI as Child & 29.5 & 30.1 & 31.7 & 33.8 & 35.0 & 37.0 & 40.0 & 45.2 & 45.7 & 47.3 & 47.3 & 47.8 \\
\hline DAC, SSI as Adult & 21.4 & 20.7 & 19.3 & 18.9 & 18.4 & 17.2 & 20.3 & 26.3 & 26.5 & 27.1 & 27.4 & 29.9 \\
\hline
\end{tabular}



Based on analysis of OASDI beneficiary records in 2009 DAF. 
Table A.3. Trends in Characteristics of Young SSD Awardees, by Subgroup, 1996-2007 (counts)



Age 18-19 at Award

\begin{tabular}{lrrrrrrrrrrrrr}
\hline All & 9,441 & 9,730 & 10,411 & 11,106 & 12,085 & 13,500 & 13,911 & 15,052 & 14,729 & 14,994 & 14,341 & 14,518 \\
Disabled Worker, No SSI & 619 & 658 & 661 & 673 & 733 & 793 & 716 & 654 & 561 & 462 & 437 & 444 \\
Disabled Worker, SSI as Child & 126 & 152 & 205 & 245 & 433 & 597 & 794 & 629 & 571 & 490 & 413 & 438 \\
Disabled Worker, SSI as Adult & 393 & 376 & 399 & 502 & 574 & 740 & 885 & 843 & 655 & 558 & 443 & 474 \\
DAC, No SSI & 4,606 & 4,718 & 4,939 & 5,042 & 5,254 & 5,683 & 5,537 & 5,857 & 5,854 & 5,768 & 5,458 & 5,002 \\
DAC, SSI as Child & 3,331 & 3,444 & 3,734 & 4,199 & 4,638 & 5,201 & 5,369 & 6,296 & 6,446 & 6,828 & 6,602 & 6,725 \\
DAC, SSI as Adult & 113 & 134 & 179 & 201 & 216 & 241 & 260 & 411 & 370 & 506 & 416 & 488
\end{tabular}

Age 20-39 at Award

\begin{tabular}{llllllllllllll}
\hline All & 138,801 & 122,783 & 122,073 & 120,939 & 122,821 & 138,538 & 146,612 & 145,685 & 143,151 & 145,625 & 136,009 & 138,502
\end{tabular}

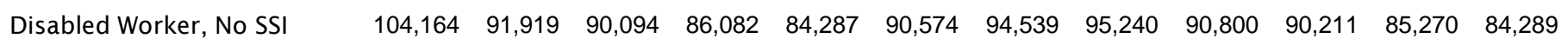

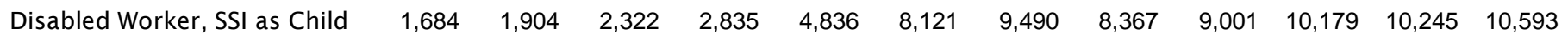



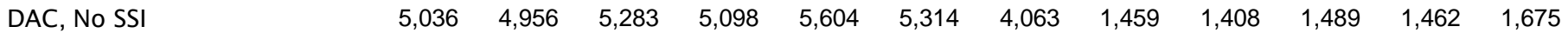

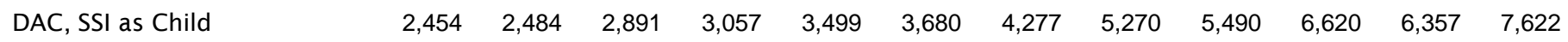

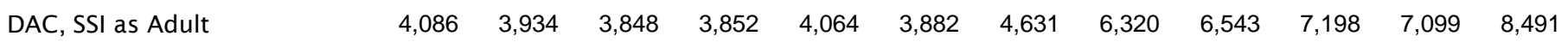

Psychiatric Disorders

\begin{tabular}{lrrrrrrrrrrrrr}
\hline All & 48,188 & 43,602 & 44,449 & 45,350 & 48,095 & 57,222 & 62,762 & 65,582 & 64,324 & 65,888 & 59,798 & 61,237 \\
Disabled Worker, No SSI & 35,918 & 32,159 & 32,131 & 31,058 & 32,107 & 36,370 & 38,836 & 40,981 & 38,914 & 39,452 & 36,054 & 35,718 \\
Disabled Worker, SSI as Child & 216 & 301 & 372 & 529 & 1,017 & 1,883 & 2,414 & 2,127 & 2,304 & 2,738 & 2,743 & 2,873 \\
Disabled Worker, SSI as Adult & 7,778 & 6,697 & 6,911 & 8,449 & 9,097 & 12,226 & 14,522 & 14,547 & 14,862 & 14,567 & 11,771 & 11,511
\end{tabular}




\begin{tabular}{|c|c|c|c|c|c|c|c|c|c|c|c|c|}
\hline DAC, No SSI & 2,230 & 2,361 & 2,693 & 2,814 & 3,064 & 3,409 & 3,274 & 3,072 & 3,067 & 3,124 & 2,985 & 2,974 \\
\hline & \multicolumn{12}{|c|}{ Intellectual Disability } \\
\hline Disabled Worker, No SSI & 3,934 & 3,350 & 3,221 & 3,028 & 3,190 & 3,355 & 3,180 & 2,709 & 2,318 & 2,133 & 1,826 & 1,755 \\
\hline Disabled Worker, SSI as Child & 825 & 922 & 1,144 & 1,418 & 2,401 & 4,078 & 4,579 & 3,670 & 3,975 & 4,485 & 4,469 & 4,616 \\
\hline Disabled Worker, SSI as Adult & 2,407 & 2,133 & 2,379 & 2,847 & 3,366 & 5,285 & 4,987 & 4,080 & 4,458 & 4,437 & 3,992 & 3,434 \\
\hline DAC, SSI as Adult & 1,901 & 1,903 & 1,789 & 1,869 & 2,026 & 1,852 & 2,283 & 3,072 & 3,136 & 3,346 & 3,264 & 3,518 \\
\hline
\end{tabular}

\section{Family Member Representative Payee}

\begin{tabular}{lrrrrrrrrrrrrrr}
\hline All & 22,845 & 21,442 & 22,691 & 23,263 & 26,150 & 31,169 & 33,445 & 33,759 & 35,223 & 37,742 & 36,504 & 39,380 \\
Disabled Worker, No SSI & 9,578 & 8,257 & 8,305 & 7,747 & 8,365 & 9,715 & 10,383 & 10,753 & 10,432 & 10,729 & 9,975 & 10,214 \\
Disabled Worker, SSI as Child & 429 & 509 & 675 & 877 & 1,493 & 2,736 & 3,235 & 2,640 & 2,984 & 3,553 & 3,600 & 3,847 \\
Disabled Worker, SSI as Adult & 2,922 & 2,536 & 2,779 & 3,279 & 3,747 & 5,679 & 6,440 & 5,966 & 6,570 & 6,652 & 5,834 & 5,786 \\
DAC, No SSI & 4,809 & 4,910 & 5,285 & 5,242 & 5,765 & 5,842 & 5,287 & 3,958 & 4,165 & 4,154 & 4,174 & 4,104 \\
DAC, SSI as Child & 2,763 & 2,943 & 3,369 & 3,805 & 4,225 & 4,809 & 5,256 & 6,515 & 6,902 & 7,974 & 7,909 & 8,958 \\
DAC, SSI as Adult & 2,074 & 2,020 & 1,989 & 2,010 & 2,226 & 2,067 & 2,521 & 3,543 & 3,716 & 4,128 & 4,199 & 4,780
\end{tabular}
Note: $\quad$ Based on analysis of OASDI beneficiary records in 2009 DAF. 
Table A.4. Trends in Characteristics for Young SSD Awardees, by Subgroup, 1996-2007 (percentages)

\begin{tabular}{lllllllllllll}
\hline SSD Award Year & 1996 & 1997 & 1998 & 1999 & 2000 & 2001 & 2002 & 2003 & 2004 & 2005 & 2006 & 2007
\end{tabular}

\begin{tabular}{|c|c|c|c|c|c|c|c|c|c|c|c|c|}
\hline & \multicolumn{12}{|c|}{ Female } \\
\hline$\overline{\text { All }}$ & 42.2 & 44.5 & 45.4 & 46.1 & 46.3 & 46.7 & 47.1 & 47.3 & 47.6 & 47.7 & 47.6 & $\overline{47.4}$ \\
\hline Disabled Worker, No SSI & 42.3 & 44.8 & 46.1 & 46.6 & 47.2 & 47.8 & 48.2 & 48.8 & 49.1 & 49.8 & 50.0 & 49.4 \\
\hline Disabled Worker, SSI as Child & 35.0 & 34.9 & 37.9 & 35.8 & 38.4 & 37.8 & 38.0 & 38.4 & 38.4 & 38.0 & 38.0 & 37.6 \\
\hline Disabled Worker, SSI as Adult & 41.3 & 44.9 & 45.3 & 48.2 & 48.2 & 48.8 & 49.9 & 49.3 & 49.8 & 49.8 & 49.6 & 50.2 \\
\hline DAC, No SSI & 43.0 & 43.1 & 43.5 & 43.3 & 43.3 & 44.0 & 43.4 & 43.4 & 43.2 & 43.1 & 42.7 & 42.4 \\
\hline DAC, SSI as Child & 43.2 & 43.2 & 42.7 & 43.3 & 42.9 & 42.6 & 42.3 & 41.8 & 41.9 & 41.7 & 41.4 & 43.1 \\
\hline \multirow[t]{2}{*}{ DAC, SSI as Adult } & 43.2 & 43.7 & 44.3 & 45.8 & 44.1 & 44.5 & 45.2 & 44.3 & 45.0 & 45.0 & 44.4 & 45.8 \\
\hline & \multicolumn{12}{|c|}{ Age 18-19 at Award } \\
\hline$\overline{\text { All }}$ & 6.4 & 7.3 & 7.9 & 8.4 & 9.0 & 8.9 & 8.7 & 9.4 & 9.3 & 9.3 & 9.5 & 9.5 \\
\hline Disabled Worker, No SSI & 0.6 & 0.7 & 0.7 & 0.8 & 0.9 & 0.9 & 0.8 & 0.7 & 0.6 & 0.5 & 0.5 & 0.5 \\
\hline Disabled Worker, SSI as Child & 7.0 & 7.4 & 8.1 & 8.0 & 8.2 & 6.8 & 7.7 & 7.0 & 6.0 & 4.6 & 3.9 & 4.0 \\
\hline Disabled Worker, SSI as Adult & 1.9 & 2.2 & 2.3 & 2.5 & 2.8 & 2.7 & 3.0 & 2.9 & 2.2 & 1.9 & 1.8 & 2.0 \\
\hline DAC, No SSI & 47.8 & 48.8 & 48.3 & 49.7 & 48.4 & 51.7 & 57.7 & 80.1 & 80.6 & 79.5 & 78.9 & 74.9 \\
\hline DAC, SSI as Child & 57.6 & 58.1 & 56.4 & 57.9 & 57.0 & 58.6 & 55.7 & 54.4 & 54.0 & 50.8 & 50.9 & 46.9 \\
\hline \multirow[t]{2}{*}{ DAC, SSI as Adult } & 2.7 & 3.3 & 4.4 & 5.0 & 5.0 & 5.8 & 5.3 & 6.1 & 5.4 & 6.6 & 5.5 & 5.4 \\
\hline & \multicolumn{12}{|c|}{ Age 20-39 at Award } \\
\hline$\overline{\text { All }}$ & 93.6 & 92.7 & 92.1 & 91.6 & 91.0 & 91.1 & 91.3 & 90.6 & 90.7 & 90.7 & 90.5 & 90.5 \\
\hline Disabled Worker, No SSI & 99.4 & 99.3 & 99.3 & 99.2 & 99.1 & 99.1 & 99.2 & 99.3 & 99.4 & 99.5 & 99.5 & 99.5 \\
\hline Disabled Worker, SSI as Child & 93.0 & 92.6 & 91.9 & 92.0 & 91.8 & 93.2 & 92.3 & 93.0 & 94.0 & 95.4 & 96.1 & 96.0 \\
\hline Disabled Worker, SSI as Adult & 98.1 & 97.8 & 97.7 & 97.5 & 97.2 & 97.3 & 97.0 & 97.1 & 97.8 & 98.1 & 98.2 & 98.0 \\
\hline DAC, No SSI & 52.2 & 51.2 & 51.7 & 50.3 & 51.6 & 48.3 & 42.3 & 19.9 & 19.4 & 20.5 & 21.1 & 25.1 \\
\hline DAC, SSI as Child & 42.4 & 41.9 & 43.6 & 42.1 & 43.0 & 41.4 & 44.3 & 45.6 & 46.0 & 49.2 & 49.1 & 53.1 \\
\hline DAC, SSI as Adult & 97.3 & 96.7 & 95.6 & 95.0 & 95.0 & 94.2 & 94.7 & 93.9 & 94.6 & 93.4 & 94.5 & 94.6 \\
\hline
\end{tabular}

\section{Psychiatric Disorders}

\begin{tabular}{lcccccccccccc}
\hline All & 32.5 & 32.9 & 33.6 & 34.3 & 35.7 & 37.6 & 39.1 & 40.8 & 40.7 & 41.0 & 39.8 & 40.0 \\
Disabled Worker, No SSI & 34.3 & 34.7 & 35.4 & 35.8 & 37.8 & 39.8 & 40.8 & 42.7 & 42.6 & 43.5 & 42.1 & 42.2 \\
Disabled Worker, SSI as Child & 11.9 & 14.6 & 14.7 & 17.2 & 19.3 & 21.6 & 23.5 & 23.6 & 24.1 & 25.7 & 25.7 & 26.0 \\
Disabled Worker, SSI as Adult & 36.9 & 38.5 & 39.4 & 42.2 & 44.3 & 45.1 & 48.5 & 49.7 & 49.8 & 49.1 & 47.3 & 48.2
\end{tabular}


DAC, No SSI

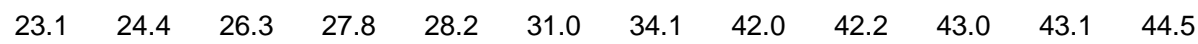

DAC, SSI as Child

$\begin{array}{llllllllllll}14.4 & 14.2 & 15.8 & 15.8 & 16.7 & 19.7 & 20.5 & 21.5 & 22.5 & 22.3 & 23.8 & 24.7\end{array}$

DAC, SSI as Adult

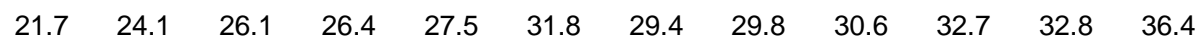

Intellectual Disability

\begin{tabular}{|c|c|c|c|c|c|c|c|c|c|c|c|c|}
\hline$\overline{\text { All }}$ & 11.7 & 12.5 & 13.0 & 13.8 & 15.3 & 16.0 & 15.2 & 13.9 & 14.5 & 15.0 & 15.2 & 15.6 \\
\hline Disabled Worker, No SSI & 3.8 & 3.6 & 3.5 & 3.5 & 3.8 & 3.7 & 3.3 & 2.8 & 2.5 & 2.4 & 2.1 & 2.1 \\
\hline Disabled Worker, SSI as Child & 45.6 & 44.8 & 45.3 & 46.0 & 45.6 & 46.8 & 44.5 & 40.8 & 41.5 & 42.0 & 41.9 & 41.8 \\
\hline Disabled Worker, SSI as Adult & 11.4 & 12.3 & 13.6 & 14.2 & 16.4 & 19.5 & 16.7 & 14.0 & 14.9 & 15.0 & 16.1 & 14.4 \\
\hline DAC, No SSI & 47.0 & 46.5 & 45.3 & 44.8 & 44.6 & 42.1 & 40.0 & 32.7 & 34.0 & 31.9 & 32.0 & 31.3 \\
\hline DAC, SSI as Child & 59.5 & 59.6 & 58.0 & 58.0 & 56.2 & 54.7 & 54.0 & 52.7 & 52.1 & 51.1 & 50.2 & 49.5 \\
\hline DAC, SSI as Adult & 45.3 & 46.8 & 44.4 & 46.1 & 47.3 & 44.9 & 46.7 & 45.6 & 45.4 & 43.4 & 43.4 & 39.2 \\
\hline & \multicolumn{12}{|c|}{ Family Member Representative Payee } \\
\hline$\overline{\text { All }}$ & 15.4 & 16.2 & 17.1 & 17.6 & 19.4 & 20.5 & 20.8 & 21.0 & 22.3 & 23.5 & 24.3 & 25.7 \\
\hline Disabled Worker, No SSI & 9.1 & 8.9 & 9.2 & 8.9 & 9.8 & 10.6 & 10.9 & 11.2 & 11.4 & 11.8 & 11.6 & 12.1 \\
\hline Disabled Worker, SSI as Child & 23.7 & 24.8 & 26.7 & 28.5 & 28.3 & 31.4 & 31.5 & 29.3 & 31.2 & 33.3 & 33.8 & 34.9 \\
\hline Disabled Worker, SSI as Adult & 13.9 & 14.6 & 15.9 & 16.4 & 18.2 & 20.9 & 21.5 & 20.4 & 22.0 & 22.4 & 23.5 & 24.2 \\
\hline DAC, No SSI & 49.9 & 50.8 & 51.7 & 51.7 & 53.1 & 53.1 & 55.1 & 54.1 & 57.4 & 57.2 & 60.3 & 61.5 \\
\hline DAC, SSI as Child & 47.8 & 49.6 & 50.9 & 52.4 & 51.9 & 54.1 & 54.5 & 56.3 & 57.8 & 59.3 & 61.0 & 62.4 \\
\hline DAC, SSI as Adult & 49.4 & 49.7 & 49.4 & 49.6 & 52.0 & 50.1 & 51.5 & 52.6 & 53.8 & 53.6 & 55.9 & 53.2 \\
\hline
\end{tabular}


Table A.5. Trends in Mean Benefit at Award for Young SSD Awardees, by Subgroup, 1996-2007 (2007 dollars)

\begin{tabular}{lccccccccccccc}
\hline SSD Award Year & 1996 & 1997 & 1998 & 1999 & 2000 & 2001 & 2002 & 2003 & 2004 & 2005 & 2006 & 2007 \\
\hline All & 736 & 722 & 716 & 719 & 724 & 718 & 726 & 741 & 741 & 733 & 732 & 725 \\
Disabled Worker, No SSI & 828 & 815 & 813 & 831 & 851 & 866 & 878 & 886 & 894 & 884 & 876 & 872 \\
Disabled Worker, SSI as Child & 473 & 459 & 450 & 448 & 450 & 440 & 457 & 506 & 514 & 519 & 520 & 520 \\
Disabled Worker, SSI as Adult & 518 & 501 & 495 & 492 & 490 & 477 & 491 & 519 & 524 & 541 & 535 & 533 \\
DAC, No SSI & 633 & 646 & 660 & 669 & 679 & 693 & 686 & 631 & 642 & 647 & 659 & 652 \\
DAC, SSI as Child & 351 & 349 & 348 & 352 & 358 & 362 & 386 & 418 & 419 & 423 & 433 & 428 \\
DAC, SSI as Adult & 460 & 449 & 447 & 454 & 462 & 461 & 549 & 629 & 629 & 629 & 631 & 626
\end{tabular}
Note: $\quad$ Based on analysis of OASDI beneficiary records in 2009 DAF. 
Table A.6. Trends in Longitudinal Outcomes in Fifth Post-Award Year for Young SSD Awardees, by Subgroup, 1996-2004 (percentages)

\begin{tabular}{|c|c|c|c|c|c|c|c|c|c|}
\hline SSD Award Year & 1996 & 1997 & 1998 & 1999 & 2000 & 2001 & 2002 & 2003 & 2004 \\
\hline \multicolumn{10}{|c|}{ Cumulative Mortality } \\
\hline$\overline{\text { All }}$ & 10.0 & 9.1 & 8.6 & 8.6 & 8.4 & 7.8 & 7.5 & 7.4 & 7.3 \\
\hline Disabled Worker, No SSI & 10.6 & 9.9 & 9.6 & 10.0 & 10.3 & 9.9 & 9.5 & 9.1 & 9.3 \\
\hline Disabled Worker, SSI as Child & 3.5 & 3.6 & 4.1 & 2.8 & 2.5 & 2.3 & 2.8 & 3.0 & 2.8 \\
\hline Disabled Worker, SSI as Adult & 14.0 & 12.8 & 11.0 & 9.3 & 8.1 & 6.6 & 6.2 & 6.8 & 6.2 \\
\hline DAC, No SSI & 1.7 & 1.6 & 1.8 & 2.2 & 2.2 & 2.7 & 2.8 & 3.0 & 2.5 \\
\hline DAC, SSI as Child & 3.9 & 4.6 & 4.7 & 3.9 & 3.6 & 3.5 & 3.3 & 3.4 & 3.5 \\
\hline DAC, SSI as Adult & 6.3 & 6.3 & 5.7 & 5.8 & 4.5 & 4.1 & 4.0 & 3.9 & 4.4 \\
\hline
\end{tabular}

Annual Percentage Receiving SSI Payments

\begin{tabular}{|c|c|c|c|c|c|c|c|c|c|}
\hline$\overline{\text { All }}$ & 23.0 & 24.8 & 26.3 & 26.8 & 26.4 & 27.9 & 26.9 & 26.5 & 26.5 \\
\hline Disabled Worker, No SSI & 10.3 & 11.6 & 12.3 & 10.7 & 9.4 & 8.4 & 8.2 & 8.9 & 8.2 \\
\hline Disabled Worker, SSI as Child & 57.1 & 60.8 & 62.0 & 59.9 & 57.6 & 58.0 & 53.0 & 48.3 & 47.3 \\
\hline Disabled Worker, SSI as Adult & 61.5 & 66.2 & 67.7 & 67.8 & 64.5 & 65.3 & 60.7 & 58.4 & 57.0 \\
\hline DAC, No SSI & 12.3 & 13.2 & 14.3 & 15.6 & 14.9 & 17.3 & 19.5 & 28.6 & 26.5 \\
\hline DAC, SSI as Child & 78.3 & 77.9 & 80.2 & 79.3 & 76.9 & 75.8 & 70.9 & 64.9 & 65.1 \\
\hline DAC, SSI as Adult & 78.9 & 79.8 & 80.9 & 77.6 & 75.0 & 73.2 & 55.0 & 40.9 & 39.5 \\
\hline \multicolumn{10}{|c|}{ Cumulative Percentage with DI STW } \\
\hline$\overline{\text { All }}$ & 11.4 & 11.4 & 10.4 & 9.8 & 9.2 & 8.9 & 9.4 & 9.3 & 8.9 \\
\hline Disabled Worker, No SSI & 13.2 & 13.4 & 12.3 & 11.5 & 10.4 & 9.9 & 9.8 & 10.1 & 9.6 \\
\hline Disabled Worker, SSI as Child & 22.3 & 19.3 & 16.9 & 17.2 & 18.1 & 16.7 & 18.7 & 18.4 & 16.9 \\
\hline Disabled Worker, SSI as Adult & 9.9 & 10.3 & 9.6 & 9.5 & 10.1 & 9.4 & 10.4 & 10.1 & 9.8 \\
\hline DAC, No SSI & 3.3 & 3.2 & 2.5 & 2.5 & 2.5 & 2.3 & 2.7 & 3.5 & 3.4 \\
\hline DAC, SSI as Child & 1.8 & 1.8 & 1.8 & 2.2 & 1.9 & 2.2 & 2.5 & 2.9 & 2.8 \\
\hline DAC, SSI as Adult & 1.1 & 1.1 & 1.2 & 1.6 & 1.3 & 1.5 & 1.6 & 1.6 & 1.8 \\
\hline
\end{tabular}

Cumulative DI NSTW Months per 1,000 Awardees

\begin{tabular}{lccccccccc}
\hline All & 216 & 223 & 203 & 188 & 172 & 157 & 162 & 162 & 163 \\
Disabled Worker, No SSI & 255 & 269 & 248 & 230 & 203 & 183 & 178 & 179 & 181 \\
Disabled Worker, SSI as Child & 453 & 381 & 291 & 302 & 331 & 279 & 325 & 330 & 304 \\
Disabled Worker, SSI as Adult & 173 & 168 & 153 & 147 & 159 & 142 & 161 & 166 & 169
\end{tabular}




\begin{tabular}{|c|c|c|c|c|c|c|c|c|c|}
\hline DAC, No SSI & 52 & 58 & 46 & 47 & 42 & 34 & 37 & 52 & 51 \\
\hline DAC, SSI as Child & 30 & 27 & 25 & 35 & 29 & 35 & 36 & 44 & 47 \\
\hline \multirow{2}{*}{ DAC, SSI as Adult } & 17 & 17 & 19 & 26 & 24 & 24 & 22 & 27 & 33 \\
\hline & \multicolumn{9}{|c|}{ Cumulative Percentage with Annual Earnings $>\$ 1,000$ (in 2007 dollars) } \\
\hline All & 39.1 & 38.2 & 36.6 & 35.7 & 35.9 & 36.5 & 37.5 & 36.0 & 34.7 \\
\hline Disabled Worker, No SSI & 40.3 & 39.2 & 37.5 & 36.1 & 35.7 & 35.6 & 35.8 & 35.2 & 33.5 \\
\hline Disabled Worker, SSI as Child & 72.0 & 72.2 & 70.8 & 71.7 & 69.8 & 65.6 & 66.9 & 62.3 & 60.2 \\
\hline Disabled Worker, SSI as Adult & 41.3 & 41.1 & 40.5 & 40.0 & 42.3 & 42.0 & 43.3 & 39.7 & 38.6 \\
\hline DAC, No SSI & 31.2 & 31.5 & 29.1 & 28.3 & 26.4 & 26.5 & 28.1 & 33.5 & 32.0 \\
\hline DAC, SSI as Child & 23.8 & 22.9 & 21.6 & 21.6 & 20.8 & 21.1 & 22.7 & 23.9 & 23.7 \\
\hline \multirow[t]{2}{*}{ DAC, SSI as Adult } & 18.4 & 19.4 & 18.1 & 16.8 & 16.3 & 17.5 & 18.0 & 18.3 & 17.4 \\
\hline & \multicolumn{9}{|c|}{ Cumulative Percentage with Annual Earnings $>12 \times S G A$} \\
\hline All & 18.8 & 16.3 & 15.1 & 13.8 & 13.3 & 13.1 & 13.7 & 13.1 & 12.1 \\
\hline Disabled Worker, No SSI & 21.6 & 19.3 & 17.9 & 16.4 & 15.5 & 15.1 & 15.2 & 14.6 & 13.5 \\
\hline Disabled Worker, SSI as Child & 30.4 & 23.0 & 20.0 & 19.9 & 21.6 & 20.5 & 22.9 & 21.4 & 19.6 \\
\hline Disabled Worker, SSI as Adult & 17.2 & 14.0 & 13.2 & 12.4 & 13.4 & 12.6 & 14.0 & 13.2 & 12.3 \\
\hline DAC, No SSI & 6.0 & 4.9 & 4.3 & 4.1 & 4.2 & 4.3 & 5.1 & 6.2 & 5.3 \\
\hline DAC, SSI as Child & 3.4 & 2.8 & 2.8 & 3.2 & 2.9 & 3.3 & 3.6 & 4.1 & 4.2 \\
\hline DAC, SSI as Adult & 2.3 & 2.2 & 2.0 & 2.6 & 2.5 & 2.7 & 2.4 & 2.9 & 3.0 \\
\hline
\end{tabular}
Note: $\quad$ Based on analysis of OASDI beneficiary records in 2009 DAF matched to MEF data. 